\title{
Differential Regulation of Human Ether-à-Go-Go-Related Gene (hERG) Current and Expression by Activation of Protein Kinase $\mathrm{C}$
}

\author{
Morgan E. Sutherland-Deveen, Tingzhong Wang, Shawn M. Lamothe, Jared N. Tschirhart, \\ Jun Guo, Wentao Li, Tonghua Yang, Yuan Du, and Shetuan Zhang
}

Department of Biomedical and Molecular Sciences, Queen's University, Kingston, Ontario, Canada

Received November 8, 2018; accepted April 17, 2019

\begin{abstract}
The human ether-à-go-go-related gene (hERG) encodes the channel that conducts the rapidly activating delayed rectifier potassium current $\left(\mathrm{I}_{\mathrm{Kr}}\right)$ in the heart. Reduction in $\mathrm{I}_{\mathrm{Kr}}$ causes long QT syndrome, which can lead to fatal arrhythmias triggered by stress. One potential link between stress and hERG function is protein kinase $\mathrm{C}(\mathrm{PKC})$ activation; however, seemingly conflicting results regarding $P K C$ regulation of $h E R G$ have been reported. We investigated the effects of PKC activation using phorbol 12-myristate 13-acetate (PMA) on hERG channels expressed in human embryonic kidney cell line 293 (HEK293) cells and $I_{K r}$ in isolated neonatal rat ventricular myocytes. Acute activation of PKC by PMA ( $30 \mathrm{nM}, 30$ minutes) reduced both $\mathrm{hERG}$ current ( $\left.\mathrm{l}_{\mathrm{hERG}}\right)$ and $\mathrm{I}_{\mathrm{Kr}}$. Chronic activation of PKC by PMA ( $30 \mathrm{nM}, 16$ hours) increased $\mathrm{I}_{\mathrm{Kr}}$ in cardiomyocytes and the expression level of hERG proteins;
\end{abstract}

\section{Introduction}

The human ether-à-go-go-related gene ( $h E R G)$ encodes the pore-forming subunit of the channel that conducts the rapidly activating delayed rectifier potassium current $\left(\mathrm{I}_{\mathrm{Kr}}\right)$ in the heart (Sanguinetti et al., 1995; Trudeau et al., 1995). $\mathrm{I}_{\mathrm{Kr}}$ is crucial for cardiac repolarization and participates in determining action potential duration. Loss of function in hERG channels attributable to genetic mutations or medications results in long QT syndrome (LQTS), which predisposes affected individuals to potentially fatal cardiac arrhythmias (Curran et al., 1995; Keating and Sanguinetti, 2001). Thus, it is important to elucidate the intracellular signaling pathways that regulate hERG function. One pathway of interest in $\mathrm{hERG}$ regulation is the activation of protein kinase $\mathrm{C}$ (PKC). PKC activation may be the link between stress and induction of arrhythmias in settings that increase sympathetic drive such as chronic heart failure (Triposkiadis et al., 2009); however, PKC regulation of hERG is complex, and seemingly conflicting results have been reported. We have shown a PKC-mediated upregulation of hERG current $\left(\mathrm{I}_{\mathrm{hERG}}\right)$ and

This work was supported by the Canadian Institutes of Health Research [Grant MOP 72911] to S.Z.

https://doi.org/10.1124/mol.118.115188. however, chronic (30 nM, 16 hours) PMA treatment decreased $I_{h E R G}$, which became larger than untreated control IhERG after PMA removal for 4 hours. Deletion of amino acid residues 2-354 ( $\Delta 2-354$ hERG) or 1-136 of the $\mathrm{N}$ terminus ( $\triangle \mathrm{N} 136 \mathrm{hERG}$ ) abolished acute PMA (30 nM, 30 minutes)-mediated $I_{\text {hERG }}$ reduction. In contrast to wild-type hERG channels, chronic activation of PKC by PMA (30 nM, 16 hours) increased both $\Delta 2-354$ hERG and $\Delta \mathrm{N} 136$ hERG expression levels and currents. The increase in hERG protein was associated with PKC-induced phosphorylation (inhibition) of Nedd4-2, an E3 ubiquitin ligase that mediates hERG degradation. We conclude that PKC regulates $h E R G$ in a balanced manner, increasing expression through inhibiting Nedd4-2 while decreasing current through targeting a site(s) within the $\mathrm{N}$ terminus.

ABBREVIATIONS: ANOVA, analysis of variance; BFA, brefeldin A; BIM-1, bisindolylmaleimide I; CHX, cycloheximide; HEK, human embryonic kidney; hERG, human ether-à-go-go-related gene; $I_{\mathrm{hERG}}$, hERG current; $\mathrm{I}_{\mathrm{Kr}}$, rapidly activating delayed rectifier potassium current; LQTS, long QT syndrome; MEM, minimum essential medium; Nedd4-2, neural precursor cell expressed developmentally downregulated protein 4 subtype 2; PCR, polymerase chain reaction; PK, proteinase K; PKC, protein kinase C; PMA, phorbol 12-myristate 13-acetate; STN, sotrastaurin; WT, wild-type. 
demonstrated that PKC activation delayed hERG degradation through inhibiting an E3 ubiquitin ligase Nedd4-2 (neural precursor cell expressed developmentally downregulated protein 4 subtype 2), leading to increased plasma membrane expression of hERG channels.

\section{Materials and Methods}

\section{Molecular Biology}

Wild-type (WT) hERG cDNA was provided by Dr. Gail Robertson (University of Wisconsin-Madison). The hERG mutants, including $\Delta 2$ $354 \mathrm{hERG}$ (N-terminal deletion of residues 2-354), $\triangle \mathrm{N} 136 \mathrm{hERG}(\mathrm{N}$ terminal truncation of residues 1-136), as well as point mutants T74C and T74I, were created using the polymerase chain reaction (PCR) method and confirmed by DNA sequencing (GENEWIZ, South Plainfield, NJ). Lipofectamine 2000 (Thermo Fisher Scientific, Waltham, MA) was used to transfect WT and mutant channel plasmids into HEK293 cells. The HEK cell lines stably expressing WT and mutant hERG channels were created using G418 for selection $(1 \mathrm{mg} / \mathrm{ml})$ and maintenance $(0.4 \mathrm{mg} / \mathrm{ml})$. HEK cell lines were cultured in minimum essential medium (MEM) supplemented with $10 \%$ fetal bovine serum, $1 \times$ nonessential amino acids, and $1 \mathrm{mM}$ sodium pyruvate (Thermo Fisher Scientific).

\section{Cell Treatment}

PKC Activation. PMA (Sigma-Aldrich, St. Louis, MO) at various concentrations in culture media was used to activate PKC in hERGHEK cells for various periods at $37^{\circ} \mathrm{C}$. Acute treatments were 30 minutes, and chronic treatments were 4-24 hours.

PKC Inhibition. Cells were incubated with $10 \mu \mathrm{M}$ bisindolylmaleimide I (BIM-1), $200 \mathrm{nM}$ Gö 6983, or $200 \mathrm{nM}$ sotrastaurin (STN) in culture media to inhibit PKC activation.

Analysis of Isolated Plasma Membrane Proteins. Surface hERG proteins were isolated using the Pierce cell-surface protein isolation kit (89881; Thermo Fisher Scientific). Briefly, surface proteins of intact cells were labeled with Sulfo-NHS-SS-Biotin for 30 minutes at $4^{\circ} \mathrm{C}$. The quenching solution was then added to cease the labeling reaction. Biotinylated proteins were isolated by binding to avidin agarose and eluted using SDS-PAGE sample buffer containing dithiothreitol. The isolated cell-surface proteins were analyzed via Western blot analysis.

Cleavage of Cell Surface. Live hERG-HEK cells were treated for 20 minutes with $200 \mu \mathrm{g} / \mathrm{ml}$ proteinase K (P6556; Sigma-Aldrich) in culture media to cleave cell-surface hERG. The reaction was stopped by the addition of $1.8 \mathrm{mM}$ EDTA and $55 \mu \mathrm{M}$ phenylmethylsulfonyl fluoride (Sigma-Aldrich) before lysis and collection of whole-cell proteins.

Measurement of hERG Degradation Rate. hERG-HEK cells were treated with $10 \mu \mathrm{M}$ brefeldin A (BFA, B6542; Sigma-Aldrich) and $10 \mu \mathrm{g} / \mathrm{ml}$ cycloheximide (CHX, 01810; Sigma-Aldrich) in culture media to inhibit transport of proteins from the endothelial reticulum to the Golgi apparatus and prevent protein synthesis, respectively. The rate of degradation of hERG proteins was assessed by comparing amounts of mature hERG remaining after 6 hours of culture between cells treated with BFA + CHX (as control) and those treated with BFA + CHX plus PMA (30 nM).

Neonatal Rat Ventricular Myocyte Isolation and Culture. Experiments using rats were approved by the Queen's University animal care committee and conducted in conformity with the Canadian Council on Animal Care. Sprague-Dawley neonatal rats of either sex at 1 day of age were sacrificed by decapitation, followed by heart removal. Ventricular myocytes were isolated by enzymatic dissociation, as described in detail (Tschirhart et al., 2019). Myocytes were cultured in $10 \%$ fetal bovine serum-containing Dulbecco's modified Eagle's medium/Ham's F-12 medium (Invitrogen, Burlington, ON) on coverslips overnight. Various treatments were then performed, and $\mathrm{Cs}^{+}$-mediated $\mathrm{I}_{\mathrm{Kr}}$ was recorded (Zhang, 2006; Guo et al., 2007).

\section{Patch-Clamp Recording}

$\mathrm{I}_{\mathrm{hERG}}$ was recorded using the whole-cell voltage-clamp method. The pipette solution consisted of (in $\mathrm{mM}$ ) the following: $135 \mathrm{KCl}, 5$ EGTA, 5 MgATP, and 10 HEPES ( $\mathrm{pH} 7.2$ with $\mathrm{KOH}$ ). The bath solution consisted of (in millimolars) of the following: $135 \mathrm{NaCl}, 5 \mathrm{KCl}$, 10 HEPES, 10 glucose, $1 \mathrm{MgCl}_{2}$, and $2 \mathrm{CaCl}_{2}$ (pH 7.4 with $\mathrm{NaOH}$ ). To elicit hERG current, cells were depolarized to voltages between -70 and $70 \mathrm{mV}$ in $10-\mathrm{mV}$ increments for 4 seconds and then repolarized to $-50 \mathrm{mV}$ for 5 seconds before returning to the holding potential of $-80 \mathrm{mV}$. $\mathrm{I}_{\mathrm{hERG}}$ amplitude for WT and N-deletion/truncation hERG were analyzed using the peak tail current following the $50 \mathrm{mV}$ depolarizing step. Activation-voltage relationships were constructed by normalizing peak tail current at each depolarizing step to that at $50 \mathrm{mV}$ depolarization. Voltage of half-activation $\left(V_{1 / 2}\right)$ was determined by fitting the activation-voltage relationships to the Boltzmann function (Gang and Zhang, 2006). For recordings of native $\mathrm{I}_{\mathrm{Kr}}$ in cultured neonatal rat ventricular myocytes, the pipette solution contained (in $\mathrm{mM}) 135 \mathrm{CsCl}, 5 \mathrm{MgATP}, 10 \mathrm{EGTA}$, and 10 HEPES (pH 7.2 with $\mathrm{CsOH}$ ). The bath solution contained (in $\mathrm{mM}$ ) $135 \mathrm{CsCl}, 1 \mathrm{MgCl}_{2}$, 10 glucose, 10 HEPES, and $10 \mu \mathrm{M}$ nifedipine ( $\mathrm{pH} 7.4$ with $\mathrm{CsOH}$ ). From a holding potential of $-80 \mathrm{mV}$, the $\mathrm{Cs}^{+}$-mediated $\mathrm{I}_{\mathrm{Kr}}$ was evoked by depolarizing steps to voltages between -70 and $70 \mathrm{mV}$ in $10-\mathrm{mV}$ increments for 1 second. Tail currents upon repolarization to the holding potential of $-80 \mathrm{mV}$ were plotted against depolarizing steps to construct tail current-voltage relationships in control and treated groups of ventricular myocytes (Zhang, 2006; Guo et al., 2007). Patchclamp experiments were conducted at room temperature $\left(22 \pm 1^{\circ} \mathrm{C}\right)$.

\section{Western Blot Analysis}

After treatment, proteins were isolated from whole-cell lysate. Briefly, the cells were washed twice with ice-cold phosphate buffer saline (PBS) solution and collected into a 1.5- $\mathrm{ml}$ Eppendorf tube with $1 \mathrm{ml}$ of ice-cold PBS. After centrifugation at $100 \mathrm{~g}$ for 4 minutes at $4^{\circ} \mathrm{C}$, the pellets were resuspended in radioimmunoprecipitation assay lysis buffer with Complete protease inhibitor cocktail (Sigma-Aldrich). For detection of phosphorylated neural precursor cell expressed developmentally downregulated protein 4 subtype 2 (Nedd4-2), PhosSTOP phosphatase inhibitor (Roche Applied Science, Indianapolis, IN) was also added to the lysis buffer. After sonication, the lysates were centrifuged at $10,000 \mathrm{~g}$ for 10 minutes at $4^{\circ} \mathrm{C}$. The supernatants were collected, and protein concentration was determined using the DC protein assay kit (Bio-Rad, Hercules, CA). To avoid protein degradation, every step was performed on ice before the addition of SDS-PAGE (sodium dodecyl sulfate polyacrylamide gel electrophoresis) sample buffer. For each sample, $15 \mu \mathrm{g}$ of whole-cell protein was diluted in $50 \mu$ l SDS-PAGE sample buffer containing 5\% $\beta$-mercaptoethanol, boiled for 5 minutes, and loaded into an $8 \%$ polyacrylamide gel, separated by electrophoresis, and transferred overnight onto a polyvinylidene fluoride membrane. Membranes were blocked for 1 hour in $0.1 \%$ Tween 20 in Tris-buffered saline containing $5 \%$ nonfat milk. The membranes were then immunoblotted with appropriate primary antibodies for 2 hours at room temperature. Horseradish peroxidase-conjugated secondary antibodies and ECL detection kit (GE Healthcare, Little Chalfont, UK) were used to detect protein signals on X-ray film (Fuji, Minato, Toyko, Japan). The BLUeye prestained protein ladder (GeneDireX, Taiwan) was used to determine the molecular weights of proteins. For quantification of Western blot data, images on X-ray films were scanned with a high-resolution scanner (Epson Perfection V800 photo color scanner; Epson, Nagano, Japan). Band intensities from each gel, measured using Image Laboratory software (Bio-Rad Laboratories), were first normalized to actin intensities in the same lanes; the band intensities of treatment group(s) were then normalized to their respective control(s) in the same gel and expressed as relative values. 


\section{Quantitative Real-Time PCR}

Total RNA was extracted from cells using a Total RNA mini kit (Geneaid Biotech Ltd., Taiwan). RNA concentration was measured using a Nanodrop ND-1000 spectrophotometer (Nano Drop, Wilmington, DE). After treatment with DNase I (M0303S; New England Biolabs), the Omniscript reverse transcription kit (Qiagen, Hilden, Germany) was used for reverse transcription of total RNA (1 $\mu \mathrm{g})$ to cDNA. Quantitative real-time PCR was performed with TaqMan Gene Expression Master Mix (Thermo Fisher Scientific) and a Model 7500 thermal cycler (Applied Biosystems, Foster City, CA). For internal control, a housekeeping gene, GAPDH, was used. Oligonucleotide primers (hERG: Assay ID Hs04234270_g1; GAPDH: Assay ID Hs03929097_g1) were obtained from Thermo Fisher Scientific. The real-time PCR protocol was 2 minutes at $50^{\circ} \mathrm{C}$, then 10 minutes at $95^{\circ} \mathrm{C}$, followed by 40 cycles of $95^{\circ} \mathrm{C}$ for 15 seconds and $60^{\circ} \mathrm{C}$ for 1 minute. Data were calculated using the $2^{-\Delta \Delta \mathrm{CT}}$ method (Livak and Schmittgen, 2001) and expressed as fold changes of hERG normalized to GAPDH.

\section{Reagents and Antibodies}

Bisindolylmaleimide I (BIM-1, ab144264) was purchased from Abcam (Cambridge, MA). Gö 6983 (CAS no. 133053-19-7) and Sotrastaurin (STN, also known as AEB071, CAS no. 425637-18-9) were purchased from Cayman Chemical Company (Ann Arbor, MI). Goat anti-hERG (C20, sc-15968, C-terminal), mouse anti-hERG (F-12, sc-377388, N-terminal), and goat anti-integrin $\beta 1$ (sc-6622) primary antibodies and mouse anti-goat IgG-HRP secondary antibody (sc2354) were purchased from Santa Cruz Biotechnology (Dallas, TX). Mouse anti-hERG (DT-331, S5-Pore linker) antibody was purchased from D.I.V.A.L. (Toscana S.R.L., Florence, Italy). Mouse anti-actin primary antibody (A4700) was purchased from Sigma-Aldrich. Rabbit antiphosphorylated Nedd4-2 (p-Nedd4-2, Ser-448, 8063S) primary antibody, horse anti-mouse (7076S), and goat anti-rabbit (7074S) secondary antibodies were purchased from Cell Signaling Technology (Danvers, MA). The PKC sampler kit containing isoenzyme specific antibodies (611421) was obtained from BD Biosciences (Franklin Lakes, NJ). Electrolytes and chemicals for patch-clamp recordings were purchased from Sigma-Aldrich.

\section{Statistical Analysis}

All data are expressed as the mean \pm S.E.M. For experiments where multiple groups were being compared with control, a one-way analysis of variance (ANOVA) with Dunnett's post-hoc test was used. For experiments with multiple groups, a one-way ANOVA with Tukey's post-hoc test was used. For experiments between two groups, a two-tailed unpaired Student's $t$ test was used. A $P$ value $\leq 0.05$ was considered statistically significant.

\section{Results}

Chronic PMA Activation Increases hERG Expression but Decreases Current. The phorbol ester PMA was used to study the effects of PKC activation on hERG-HEK cells. To observe changes in hERG expression, cells were treated with PMA, and whole-cell proteins were analyzed. On Western blots, hERG protein displays two bands with molecular masses of 135 and $155 \mathrm{kDa}$. The $135-\mathrm{kDa}$ band represents the intracellular, immature core-glycosylated form of the channel proteins; the $155-\mathrm{kDa}$ band is the mature fully glycosylated form in the plasma membrane (Zhou et al., 1998). First, we determined the time-dependent effects of PMA on hERG expression. hERG-HEK cells from the same passage were separated into culture plates and treated with 30 nM PMA. At different time points, cells were collected, and
hERG expression was examined using Western blot analysis. Goat anti-hERG antibody (C-20, C-terminal) was used as the main primary antibody. PMA (30 nM) increased hERG expression in a time-dependent manner; the increase started at 0.5 hour after treatment, became significant at 4 hours, and reached a maximal effect at 6 hours. Treatment at 12 and 24 hours caused further increases in two of five experiments; but, overall, a maximal effect was achieved 6 hours after treatment (Fig. 1A).

PMA is a PKC activator (Thomas et al., 2003; Cockerill et al., 2007). To confirm that the effects of PMA on hERG are indeed mediated by PKC activation, we used a PKC inhibitor, BIM-1, to inhibit PKC activation. The addition of BIM-1 $(10 \mu \mathrm{M})$ to PMA (30 $\mathrm{nM})$ for 6 -hour treatment abolished the PMA-mediated increase in hERG expression (Fig. 1B), indicating that PMA increases hERG expression through PKC activation. BIM-1 alone had no effect on hERG expression (Fig. 1B).

The concentration-response relationship of PMA-induced increase in hERG expression was examined by treating hERG-HEK cells with PMA for 6 hours at various concentrations. Whereas $10 \mathrm{nM}$ PMA significantly increased hERG expression and $30 \mathrm{nM}$ PMA caused a further increase in hERG expression, 100 and $1000 \mathrm{nM}$ PMA did not cause any further increase (Fig. 2A).

Increased $\mathrm{hERG}$ protein expression is usually accompanied by increased $\mathrm{I}_{\mathrm{hERG}}$. We recorded $\mathrm{I}_{\mathrm{hERG}}$ using a whole-cell voltage-clamp method. In contrast to the increased hERG expression, treatments with PMA decreased $\mathrm{I}_{\mathrm{hERG}}$. Whereas 6-hour treatment with 10 nM PMA significantly decreased $\mathrm{I}_{\mathrm{hERG}}$ and $30 \mathrm{nM}$ PMA caused a further decrease in $\mathrm{I}_{\mathrm{hERG}}, 100,300$, and $1000 \mathrm{nM}$ PMA did not cause a further decrease (Fig. 2B).

hERG Channels Are Membrane-Bound and Functional after Chronic PMA Treatment. One possible explanation for the discrepancy between increased $155-\mathrm{kDa}$ hERG expression and decreased $\mathrm{I}_{\mathrm{hERG}}$ after PMA treatment
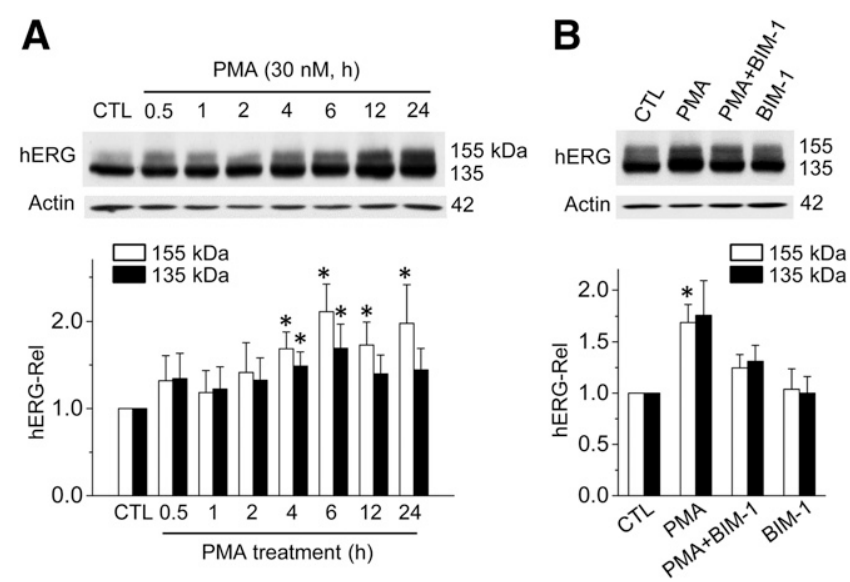

Fig. 1. PKC activation increases hERG channel expression. (A) Time course for the effect of $30 \mathrm{nM}$ PMA treatment [control (CTL), 0.5, 1, 2, 4, 6, 12,24 hours] on hERG expression ( $n=5$ independent experiments). (B) hERG expression in CTL, 6-hour PMA (30 nM), 6-hour PMA (30 nM) + BIM-1 $(10 \mu \mathrm{M})$, or 6-hour BIM-1 $(10 \mu \mathrm{M})$ treated cells $(n=6$ independent experiments). In A and B, hERG intensity is measured relative to actin and normalized to the CTL group. The $155-$ and $135-\mathrm{kDa}$ bands were analyzed independently using one-way ANOVA with Dunnett's post-hoc test. $* P<0.05$ vs. CTL. 


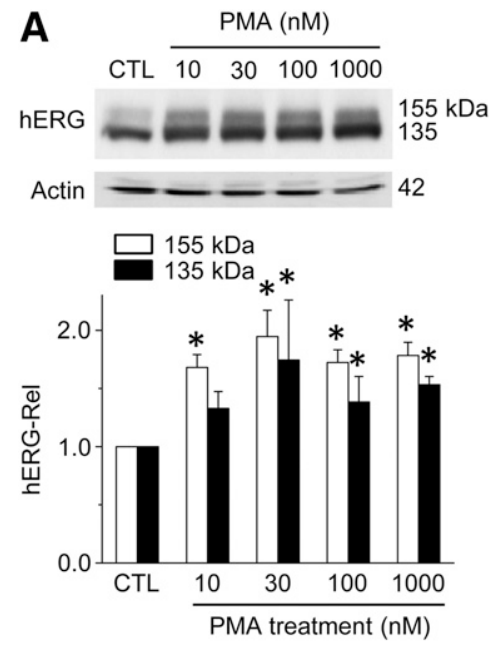

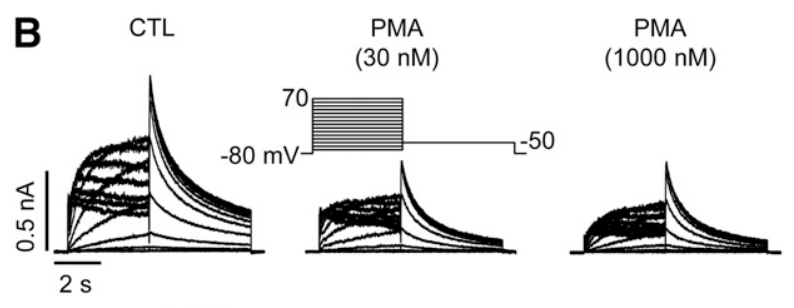

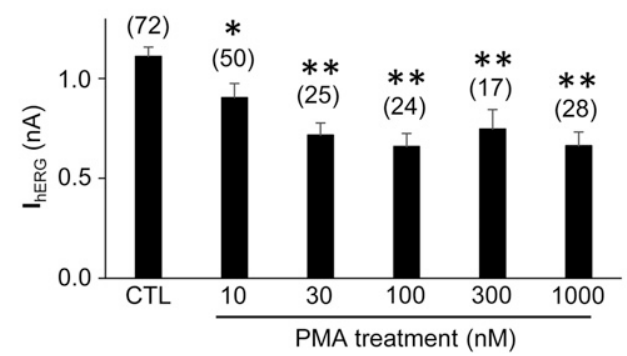

Fig. 2. PKC activation decreases $I_{\text {hERG }}$. (A) hERG expression in control (CTL) hERG-HEK cells and those treated with PMA in various concentrations for 6 hours $(n=5$ independent experiments). The 155- and $135-\mathrm{kDa}$ bands were analyzed independently using oneway ANOVA with Dunnett's post-hoc test. $* P<0.05$ vs. CTL. (B) $\mathrm{I}_{\mathrm{hERG}}$ in CTL hERG-HEK cells and those treated with PMA in various concentrations for 6 hours. Voltage protocol for recording $\mathrm{I}_{\mathrm{hERG}}$ is shown above the representative current traces. Numbers of cells recorded from eight independent experiments are shown above the summarized current amplitudes (peak tail current at $-50 \mathrm{mV}$ after $50 \mathrm{mV}$ depolarization). I $\mathrm{hERG}_{\text {fas }}$ analyzed using data from cells with one-way ANOVA with Dunnett's post-hoc test. $* P<0.05 ; * * P<0.01$ vs. CTL. is that the $155-\mathrm{kDa}$ hERG protein is not at the plasma membrane. We performed two experiments to determine whether the $155-\mathrm{kDa}$ hERG after PMA treatment (30 nM, 6 hours) is localized at the cell surface. First, we isolated cellsurface protein using a biotinylation method and examined hERG expression using Western blot analysis. PMA treatment increased the membrane-bound 155 -kDa hERG proteins (Fig. 3A). Second, we cleaved cell-surface hERG by treating hERG-HEK cells with proteinase $\mathrm{K}$ (PK, $200 \mu \mathrm{g} / \mathrm{ml}, 20 \mathrm{~min}$ utes). We previously demonstrated that PK selectively cleaves plasma-membrane-bound $155-\mathrm{kDa}$ hERG proteins without affecting the intracellularly localized immature $135-\mathrm{kDa}$ hERG proteins (Lamothe et al., 2016). The 155-kDa hERG bands, but not $135-\mathrm{kDa}$ hERG bands, in both control and
PMA-treated (30 nM, 6 hours) cells were completely cleaved by PK (Fig. 3B). Thus, the PMA-increased 155-kDa hERG is in the plasma membrane.

Mature hERG expression can be increased by two mechanisms: accelerated protein synthesis and/or decreased hERG degradation. We examined the mRNA levels in control and PMA- (30 nM, 2 and 6 hours) treated hERG-HEK cells. PMA did not increase hERG mRNA level (Fig. 3C). To determine whether PMA treatment delays degradation of mature hERG channels, we first treated hERG-HEK cells with $10 \mu \mathrm{g} / \mathrm{ml}$ cycloheximide (CHX, a protein synthesis inhibitor) and $10 \mu \mathrm{M}$ brefeldin A (BFA, an ER-to-Golgi transit inhibitor). This treatment prevents protein synthesis and forward trafficking and therefore allows for observation of the rate of degradation
A

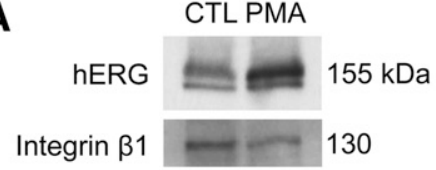

B

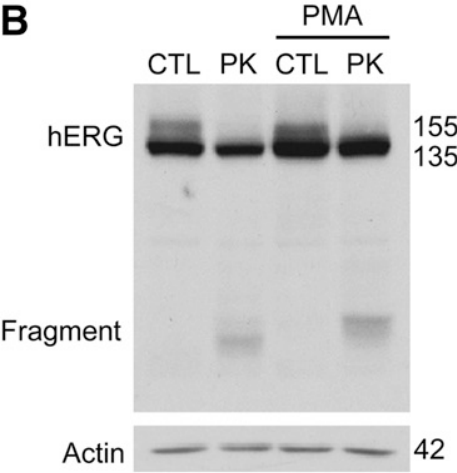

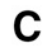

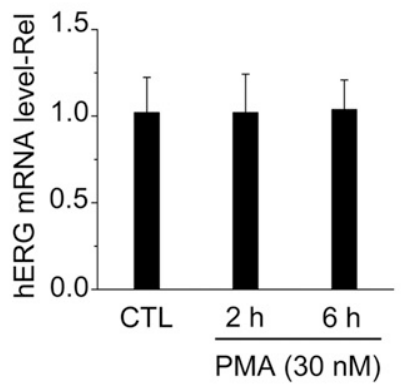

D
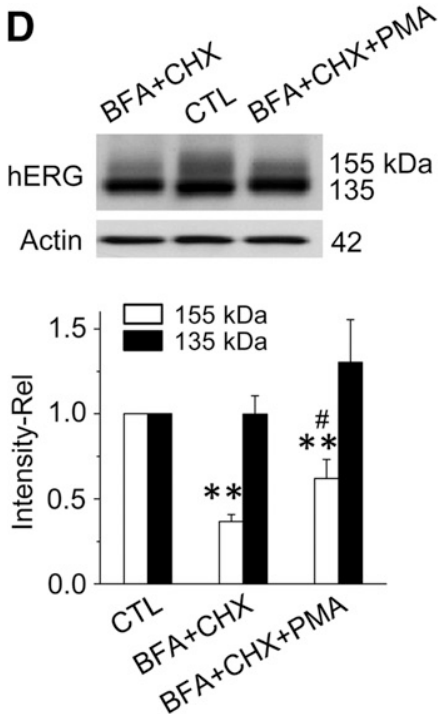
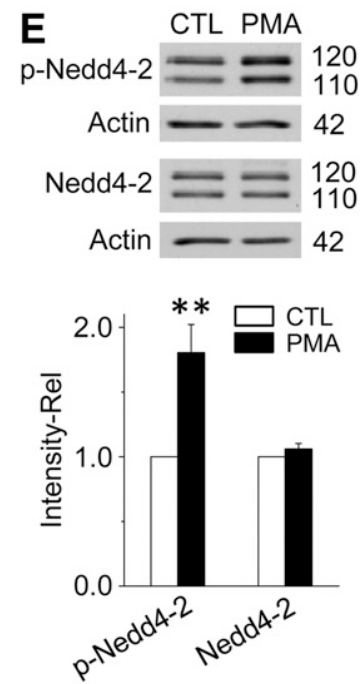

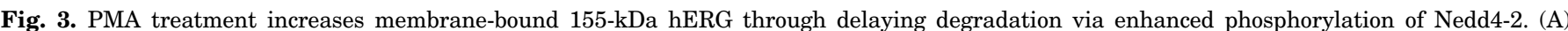

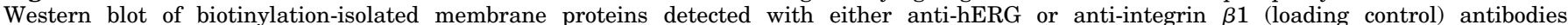

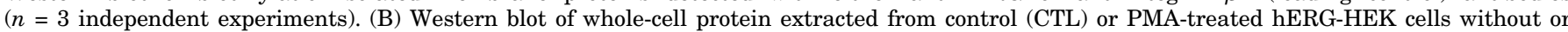

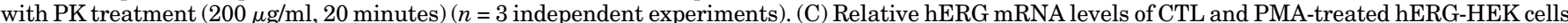

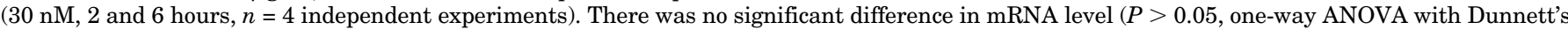

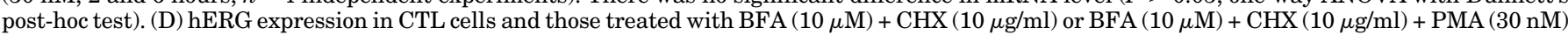

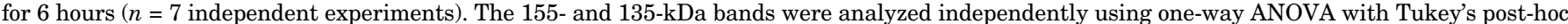

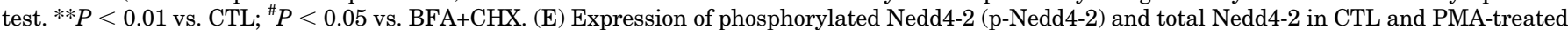

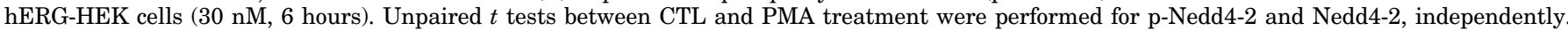
$* * P<0.01$ vs. CTL. $n=10$ independent experiments. 
of mature hERG channels. Western blot analysis of whole-cell protein revealed that, compared with cells treated with BFA and CHX, cells with additional PMA treatment had significantly more mature (155-kDa) hERG remaining after 6 hours of treatment (Fig. 3D). Thus, PMA (30 nM) delayed hERG degradation, leading to an increased membrane expression of hERG channels. We previously demonstrated that hERG degradation is mediated by the ubiquitin ligase Nedd4-2 (Guo et al., 2012). Nedd4-2 activity is controlled by phosphorylation, which leads to inhibition of its catalytic activity (Debonneville et al., 2001). To determine whether Nedd4-2 plays a role in PMA-mediated hERG increase, we examined the effects of PMA treatment (30 nM, 6 hours) on the expression levels of total and phosphorylated Nedd4-2 using Western blot analysis. PMA increased the amount of phosphorylated Nedd4-2 without affecting the amount of total Nedd4-2 protein (Fig. 3E), providing an explanation for PMA-mediated increase in hERG expression through delayed degradation.

Acute PMA Treatment Reduces $\mathbf{I}_{\mathbf{h E R G}}$. We reasoned that PKC activation may exert two independent effects on hERG channels: inhibiting channel activity and increasing protein expression. To isolate hERG inhibition from increased channel expression, we examined an acute (30-minute) treatment of hERG-HEK cells with 30 nM PMA, which does not lead to increased hERG protein expression (Fig. 1A). Acute PMA treatment decreased $\mathrm{I}_{\mathrm{hERG}}$ (Fig. 4A) and shifted the voltage of half-maximal activation $\left(V_{1 / 2}\right)$ by $10.7 \mathrm{mV}$ to the positive-voltage direction (Fig. 4B). PMA treatment did not change the slope factor of the activation curve. In an attempt to prevent the PMA-mediated effects on $\mathrm{I}_{\mathrm{hERG}}$, we used BIM-1 $(10 \mu \mathrm{M})$; however, since BIM-1 $(10 \mu \mathrm{M})$ alone inhibits $\mathrm{I}_{\mathrm{hERG}}$ (Thomas et al., 2004a), its effects on PMA-mediated $\mathrm{I}_{\mathrm{hERG}}$ reduction could not be addressed (Fig. 4A). On the other hand, although BIM-1 (10 $\mu \mathrm{M})$ treatment alone did not shift $V_{1 / 2}$ (data not shown), it prevented the PMA-mediated shift of the hERG activation curve (Fig. 4B), indicating that the PMAmediated effects on $\mathrm{I}_{\mathrm{hERG}}$ were through PKC activation.

Our data so far indicate that PMA-mediated $\mathrm{I}_{\mathrm{hERG}}$ reduction occurs in tens of minutes, but PMA-mediated increase in hERG expression occurs within hours after PMA treatment. We reasoned that, upon PMA removal, if the PMA-induced reduction in $I_{h E R G}$ recovers faster than the PMA-induced
A
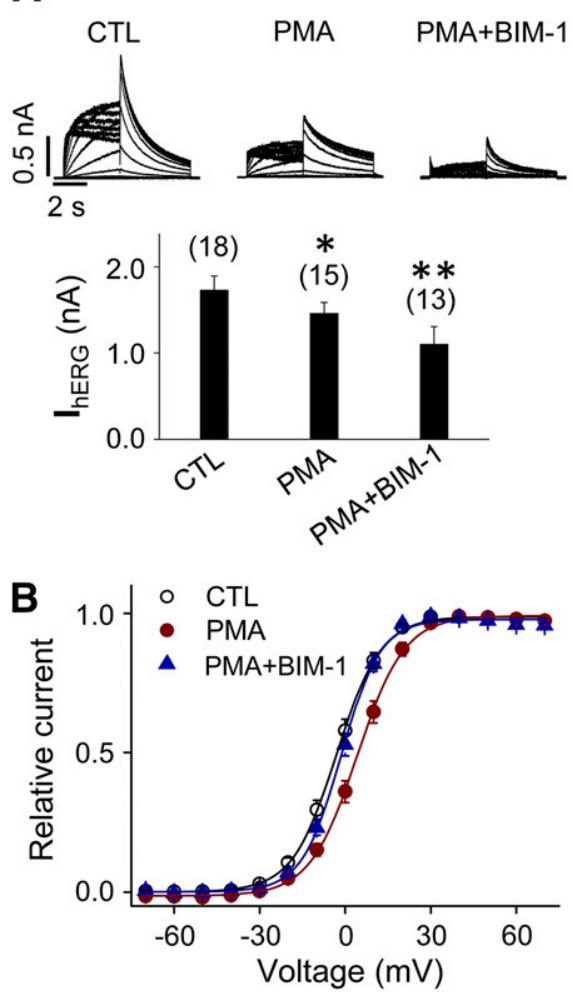

C

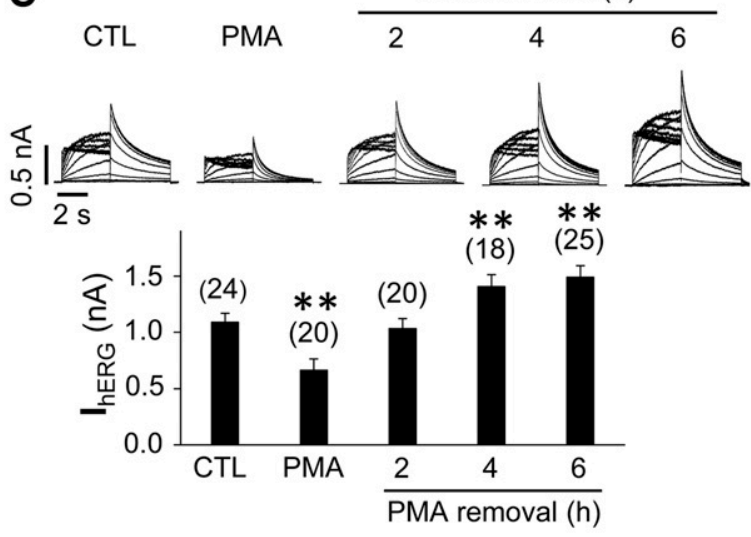

D

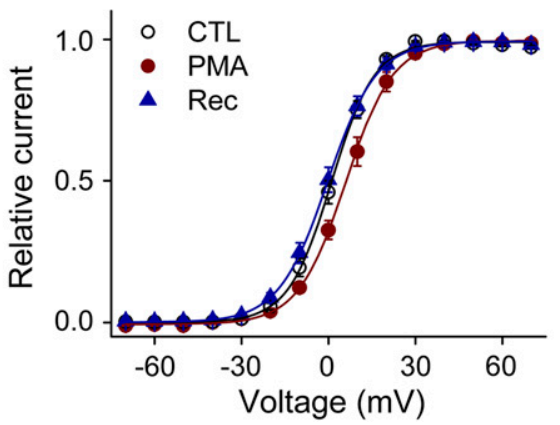

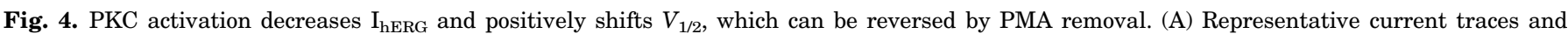

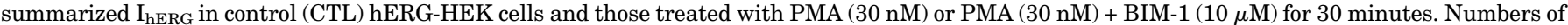

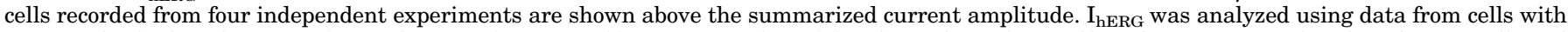

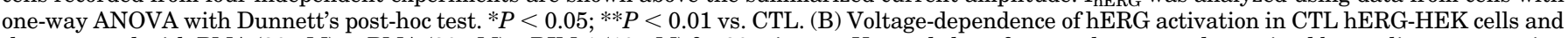

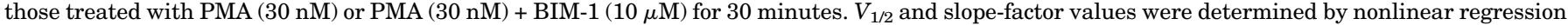

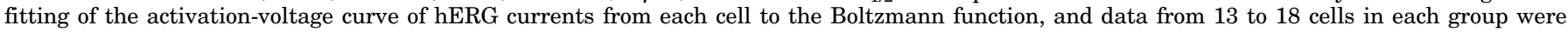

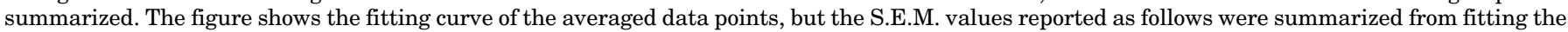

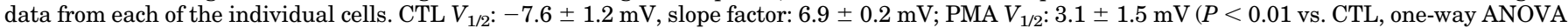

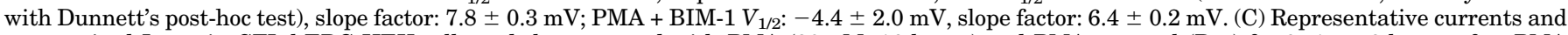

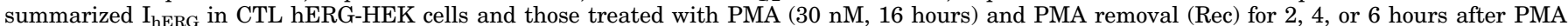

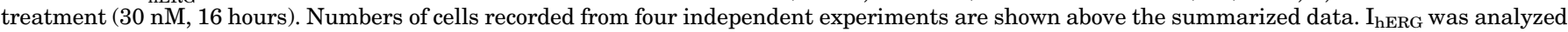

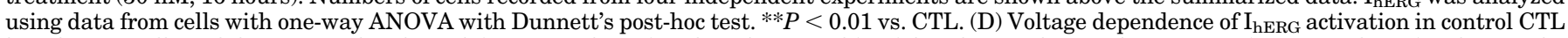

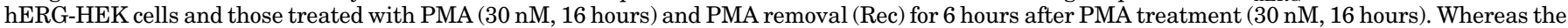

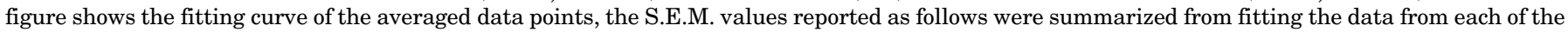

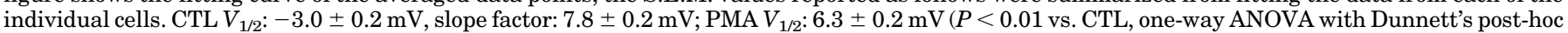
test), slope factor: $7.2 \pm 0.3 \mathrm{mV}$; Rec $V_{1 / 2}:-2.0 \pm 0.2 \mathrm{mV}$, slope factor: $8.1 \pm 0.2 \mathrm{mV}$. 
increase in hERG expression, we should be able to observe a PMA-mediated increase in $\mathrm{I}_{\mathrm{hERG}}$ associated with increased channel density. Our results showed that this is indeed the case. We treated hERG-HEK cells with PMA (30 $\mathrm{nM}$ ) for 16 hours. We then washed the cells with fresh media three times to remove PMA and continued to culture the cells in fresh media. Over the course of the next 6 hours, $\mathrm{I}_{\mathrm{hERG}}$ gradually increased to a magnitude greater than that of untreated controls (Fig. 4C). After 6-hour recovery, $V_{1 / 2}$ of $\mathrm{I}_{\text {hERG }}$ was also restored to that of untreated controls (Fig. 4D). This result is consistent with an increased abundance of functional hERG channels after PMA treatment. We propose that PKC directly inhibits hERG channels through a reversible modification. The inhibition is relieved upon PMA removal, whereas the enhanced protein expression by PMA is still maintained because of the relatively slow turnover rate of hERG channels (Ficker et al., 2003).

Acute PMA Treatment Reduces, but Chronic PMA Treatment Increases, $I_{K r}$ in Neonatal Rat Ventricular Myocytes. To determine whether the differential acute and chronic effects of PMA treatments on expressed hERG channels also apply to native cardiomyocytes, we examined the effects of PMA on $\mathrm{I}_{\mathrm{Kr}}$ in neonatal rat ventricular myocytes. Ventricular myocytes were treated with PMA $(30 \mathrm{nM})$ for either 30 minutes or 16 hours in culture conditions. After treatment, ventricular myocytes were transferred to the recording chamber. Families of $\mathrm{Cs}^{+}$-mediated $\mathrm{I}_{\mathrm{Kr}}\left(\mathrm{I}_{\mathrm{Kr}-\mathrm{Cs}}\right)$ were recorded using whole-cell voltage-clamp method. As shown in Fig. 5, whereas a 30-minute treatment with PMA decreased $\mathrm{I}_{\mathrm{Kr}}$ (Fig. 5A), a 16-hour treatment increased $\mathrm{I}_{\mathrm{Kr}}$ (Fig. 5B). These results are generally consistent with our results obtained from hERG-HEK cells. Thus, while a 30-minute treatment with PMA ( $30 \mathrm{nM}$ ) decreased both $\mathrm{I}_{\mathrm{Kr}}$ and $\mathrm{I}_{\mathrm{hERG}}$, a 16-hour treatment with PMA ( $30 \mathrm{nM})$ increased $\mathrm{I}_{\mathrm{Kr}}$ and $\mathrm{hERG}$ expression; however, a difference exists; whereas chronic (16 hours) PMA-induced increase in $\mathrm{I}_{\mathrm{hERG}}$ recorded from HEK cells is only seen after PMA removal for 4 hours (Fig. $4 \mathrm{C}$ ), chronic (16 hours) PMA-induced increase in $\mathrm{I}_{\mathrm{Kr}}$ recorded from cardiomyocytes is observed immediately after treatment (Fig. 5B).

PMA-Induced Effect on $\mathbf{I}_{\text {herG }}$ Is Mediated by PKC Activation. PMA activates not only PKC isoforms but also other proteins that are regulated by diglycerides such as Ras guanyl nucleotide-releasing protein (Ebinu et al., 2000). We showed that the PKC inhibitor BIM-1 prevented PMAinduced effects on hERG expression and activation curve of $\mathrm{I}_{\text {hERG }}$ (Fig. 1B; Fig. 4B). Whereas BIM-1 is considered a "selective" PKC inhibitor, it can also inhibit other important signaling kinases such as p70S6K and p90RSK (Alessi, 1997; Roberts et al., 2005). Furthermore, our data demonstrated that BIM-1 also directly inhibits I $_{\text {hERG }}$ (Fig. 4A). To further confirm that PKC activation is responsible for the PMAinduced effects on hERG, we examined the effects of two additional PKC inhibitors, Gö 6983 and STN, on hERG channels. Neither Gö $6983(200 \mathrm{nM})$ nor STN (200 nM) acutely affected $\mathrm{I}_{\text {hERG }}$ (data not shown), but both completely prevented acute PMA treatment ( 30 minutes, $30 \mathrm{nM}$ ) induced $\mathrm{I}_{\mathrm{hERG}}$ reduction (Fig. 6A), and chronic PMA treatment (16 hours, $30 \mathrm{nM}$ ) induced an $\mathrm{I}_{\mathrm{hERG}}$ increase after 6-hour PMA removal (Fig. 6B). Western blot analysis showed that they also prevented chronic PMA treatment (16 hours, $30 \mathrm{nM}$ )induced increase in hERG protein expression (Fig. 6C). These
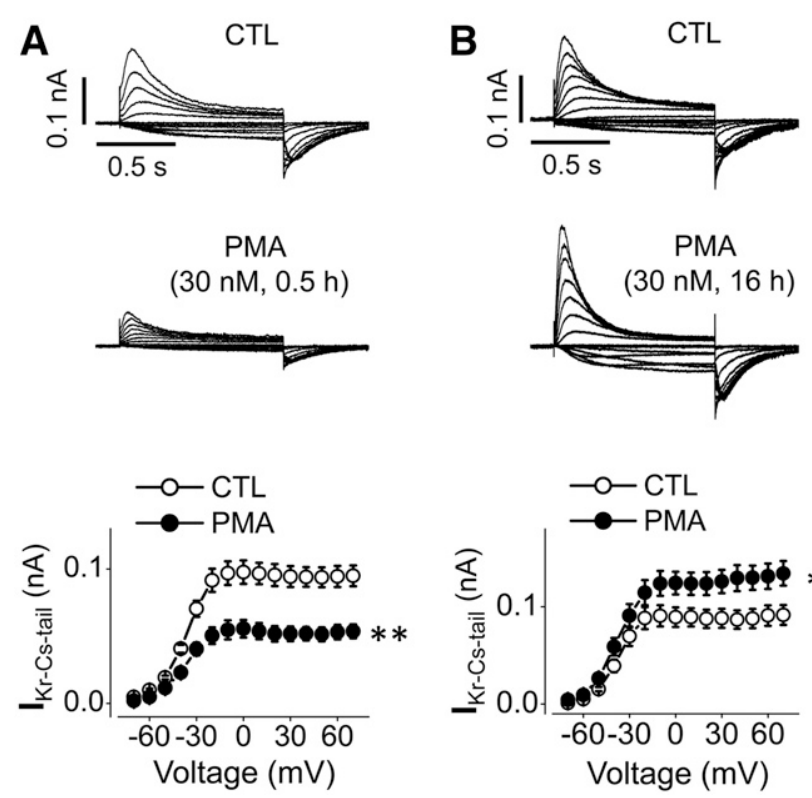

Fig. 5. PMA treatment acutely decreases, but chronically increases, $\mathrm{I}_{\mathrm{Kr}}$ of neonatal rat ventricular myocytes. Neonatal rat ventricular myocytes were treated with PMA (30 nM) for 30 minutes (A) or 16 hours (B). Representative current traces are displayed along with summarized tail current-voltage relationships. In (A), $n=27$ for control (CTL) and $n=28$ for acutely PMA-treated cells from three independent experiments. Unpaired $t$ tests between CTL and PMA treatment at each of the depolarizing voltages were performed. $* * P<0.01$ vs. CTL at voltages $\geq-30 \mathrm{mV}$. In (B) $n=21$ for CTL, $n=27$ for chronic PMA-treated cells from four independent experiments. Unpaired $t$ tests between control CTL and PMA treatment at each of the depolarizing voltages were performed. $* * P<0.01$ vs. CTL at voltages $\geq-30 \mathrm{mV}$.

results further indicate that PMA-mediated changes in hERG are through $\mathrm{PKC}$ activation.

PMA-Mediated Effects on hERG Expressed in HEK Cells May Not Be due to the PKC Depletion. There are various $\mathrm{PKC}$ isoforms. To investigate the effects of PMA treatment on the expression of PKC isoforms in our hERG-HEK cells, we used a PKC sampler kit containing isoenzyme-specific antibodies (611421; BD Biosciences). As can been seen in Fig. 7, with the isoform-specific antibodies of the kit, all PKC isoforms were detected. Treatment of hERG-HEK cells with $30 \mathrm{nM}$ PMA for up to 24 hours caused a time-dependent depletion of the expression level of PKC $\alpha$ and PKC $\theta$ and did not affect the expressions of PKC $\beta, P K C \varepsilon$, $\mathrm{PKC} \sigma, \mathrm{PKC} \iota$, and $\mathrm{PKC} \lambda$ up to 18 hours (Fig. 7); however, 30 nM PMA treatment of 6 hours did not cause depletion of any PKC isoenzymes (Fig. 7).

The N Terminus of hERG Is Required for PKCMediated Inhibition of Current but not Channel Expression. We investigated the molecular mechanisms underlying PMA-mediated $\mathrm{I}_{\mathrm{hERG}}$ reduction. Previous studies have suggested that the $\mathrm{N}$ terminus of hERG is required for PKC-mediated $\mathrm{I}_{\mathrm{hERG}}$ reduction (Cockerill et al., 2007; Liu et al., 2017). We obtained novel evidence that the $\mathrm{N}$ terminus is involved in PMA-mediated $\mathrm{I}_{\mathrm{hERG}}$ reduction. As shown in Fig. 8A, after a 6-hour PMA (30 nM) treatment, an increase in 155-kDa hERG expression was observed using either an anti-C-terminus or anti-S5-pore hERG antibody; however, a decrease in 155-kDa hERG was observed when an anti$\mathrm{N}$-terminus hERG antibody was used in the same samples (Fig. 8A). We believe activation of PKC modifies the $\mathrm{N}$ terminus 

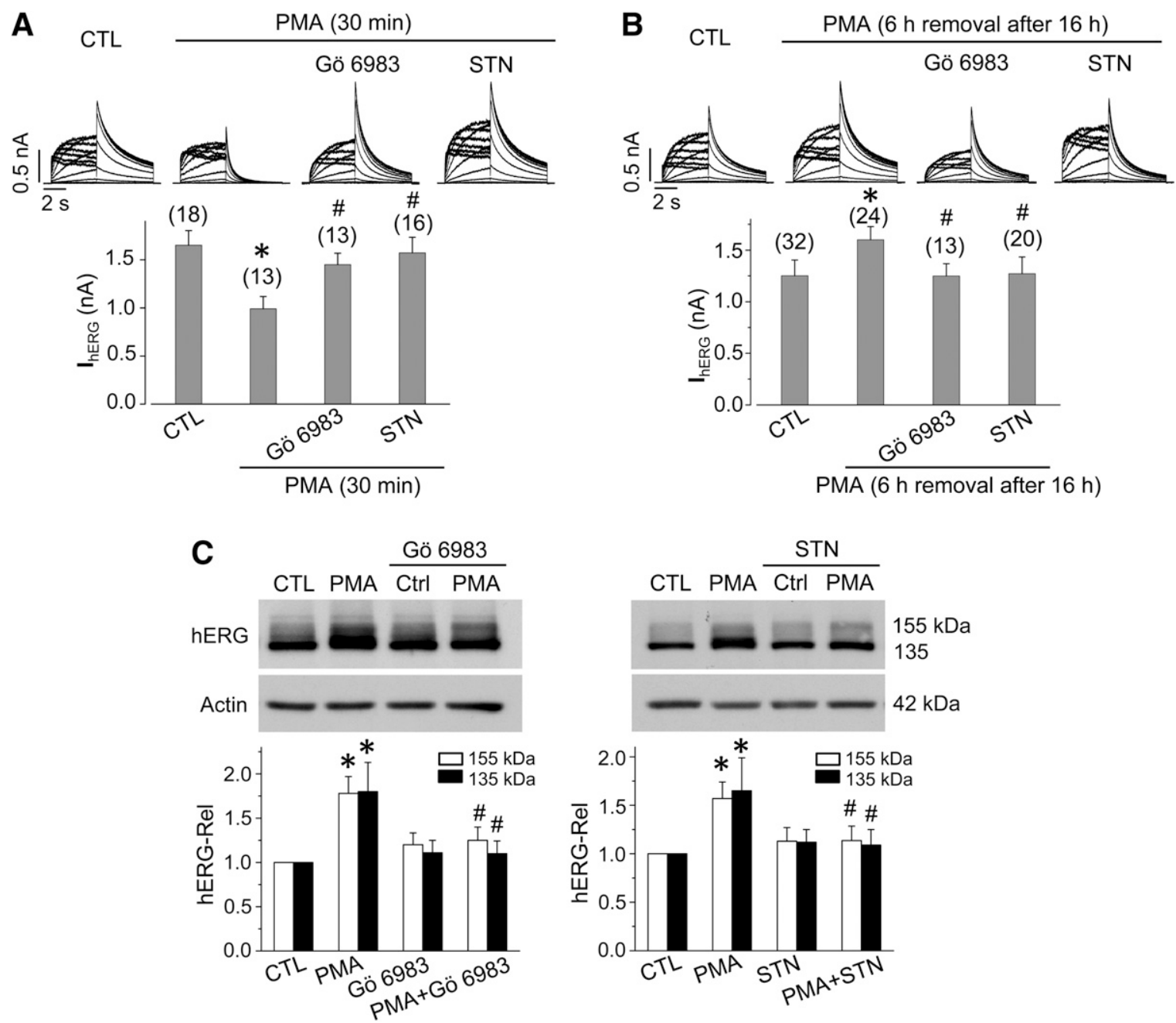

Fig. 6. PKC inhibitors Gö 6983 and STN prevent acute PMA-mediated $\mathrm{I}_{\mathrm{hERG}}$ reduction and chronic PMA-mediated $\mathrm{I}_{\mathrm{hERG}} / \mathrm{hERG}$ channel increase. (A) Representative current traces and summarized $\mathrm{I}_{\mathrm{hERG}}$ in control (CTL) hERG-HEK cells and those acutely (30 minutes) treated with PMA (30 nM), PMA $(30 \mathrm{nM})+$ Gö $6983(200 \mathrm{nM})$, or PMA $(30 \mathrm{nM})+$ STN $(200 \mathrm{nM})$. Numbers of cells recorded from four independent experiments are shown above the summarized current amplitudes. $\mathrm{I}_{\mathrm{hERG}}$ was analyzed using data from cells with one-way ANOVA with Tukey's post-hoc test $\left({ }^{*} P<0.05 \mathrm{vs}\right.$. CTL; ${ }^{\#} P<0.05$ vs. PMA). (B) Representative current traces and summarized $\mathrm{I}_{\mathrm{hERG}}$ in control CTL hERG-HEK cells and those 6 hours after drug removal aftere chronic (16 hours) treatments with PMA (30 nM), PMA (30 nM) + Gö $6983(200 \mathrm{nM})$, or PMA (30 nM) + STN (200 nM). Numbers of cells recorded from four independent experiments are shown above the summarized data. I $\mathrm{I}_{\mathrm{HER}}$ was analyzed using data from cells with one-way ANOVA with Tukey's post-hoc test ( ${ }^{*} P<0.05$ vs. CTL; ${ }^{\#} P<0.05$ vs. PMA). (C) hERG expression in CTL hERG-HEK cells and those chronically (16 hours) treated with PMA (30 nM), PMA (30 nM) + Gö $6983(200 \mathrm{nM})$, or PMA $(30 \mathrm{nM})+$ STN $(200 \mathrm{nM})$. The 155- and 135-kDa bands were analyzed independently using one-way ANOVA with Tukey's post-hoc test. ${ }^{*} P<0.05$ vs. CTL; ${ }^{\#} P<0.05$ vs. PMA. $n=4$ independent experiments.

of hERG, and such modification interferes with binding of the $\mathrm{N}$-terminal targeting antibody to the protein, resulting in decreased hERG detection despite the increase in overall hERG expression. We then investigated the correlation between PMAmediated reduction in $\mathrm{I}_{\mathrm{hERG}}$ and a decrease in $155-\mathrm{kDa} \mathrm{hERG}$ detection with the anti-N-terminal antibody. As shown in Fig. $8 \mathrm{~B}$, Western blot analysis using the anti-C-terminus antibody did not reveal a significant change in $155-\mathrm{kDa}$ hERG expression after PMA ( $30 \mathrm{nM}$ ) treatment up to 60 minutes; however, PMA $(30 \mathrm{nM})$-mediated reduction in $155-\mathrm{kDa}$ detection with the anti$\mathrm{N}$-terminus antibody started upon 20-minute treatment and was more obvious upon 30- and 60-minute treatments. This time course is consistent with PMA-mediated reduction in $\mathrm{I}_{\mathrm{hERG}}$, indicating that modification of the $\mathrm{N}$ terminus is associated with PKC-mediated $\mathrm{I}_{\mathrm{hERG}}$ reduction. This notion is further supported by our data shown in Fig. 8C. After a 16-hour treatment of hERGHEK cells with PMA ( $30 \mathrm{nM}$ ), Western blot analysis using the
anti-C-terminus antibody revealed an increased hERG expression. In contrast, Western blot analysis of the same protein samples using the anti-N-terminus antibody revealed a decreased hERG (155-kDa) expression, indicating that PMAinduced PKC activation modified the $\mathrm{N}$ terminus of the channel. Upon removal of PMA, the 155-kDa hERG expression detected with the anti-C-terminus antibody remained at an increased level up to 6 hours. Intriguingly, the decreased 155-kDa hERG detection with the anti-N-terminus antibody recovered significantly at 4 and 6 hours after PMA removal (Fig. 8C), a time course similar to the recovery of $\mathrm{I}_{\mathrm{hERG}}$ upon PMA removal (Fig. 4C). These observations support the notion that modification of the $\mathrm{N}$ terminus by PMA is involved in hERG channel inhibition, and recovery from this inhibition leads to an increase in $\mathrm{I}_{\mathrm{hERG}}$ (Fig. 4C) associated with increased protein expression.

To investigate more completely the role of the $\mathrm{N}$ terminus in PMA-mediated $\mathrm{I}_{\mathrm{hERG}}$ inhibition, we deleted amino acid 


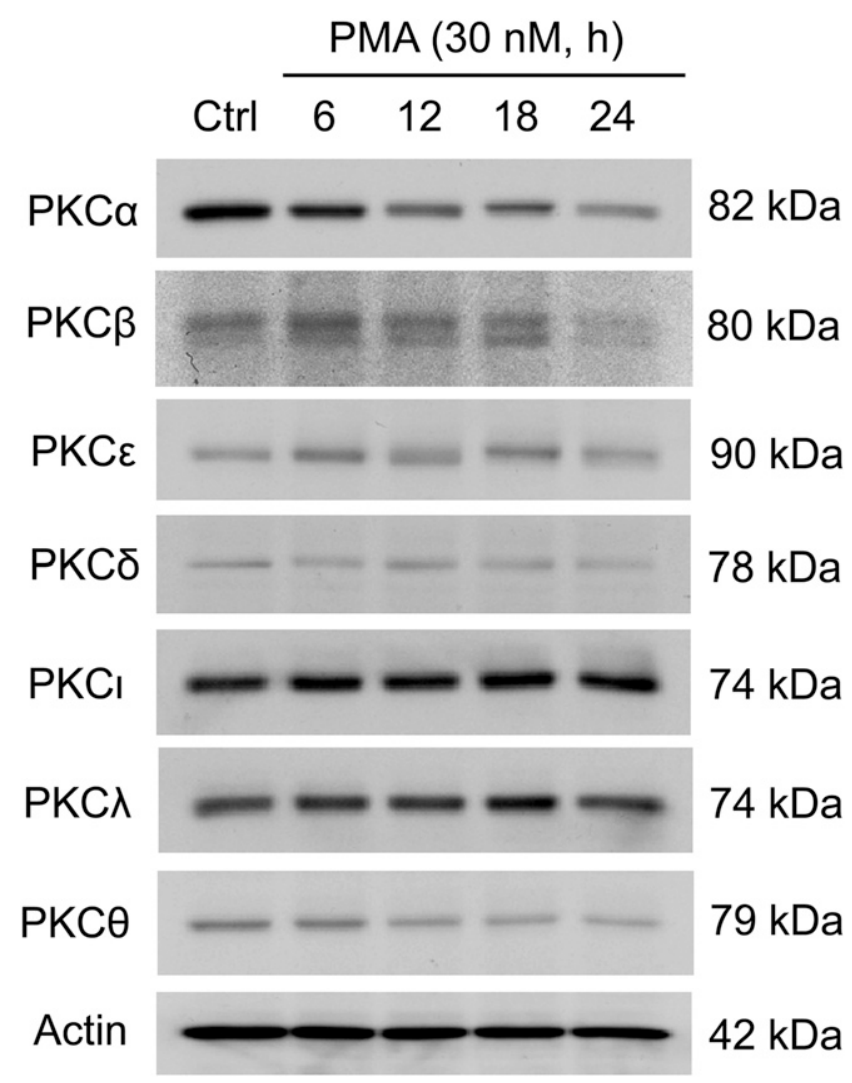

Fig. 7. Effects of PMA treatment on PKC isozymes in hERG-HEK cells. hERG-HEK cells were treated with $30 \mathrm{nM}$ PMA for various periods. Wholecell lysates were extracted, and expressions of PKCs were detected using isozyme-specific antibodies. Consistent results were obtained in three independent experiments.

residues $2-354$ of the $\mathrm{N}$ terminus of hERG to construct the $\Delta 2$ 354 hERG mutant. This mutant was developed based on previous studies showing that the $\Delta 2-354$ hERG mutant produces functional channels (Wang et al., 1998). In contrast to the effects on WT hERG, acute treatment of $\Delta 2-354 \mathrm{hERG}$ cells with PMA ( $30 \mathrm{nM}, 30$ minutes) had no effect on either the current amplitude (Fig. 9A) or the $V_{1 / 2}$ of $\Delta 2-354$ hERG channels (Fig. 9B). On the other hand, the $\mathrm{N}$ terminus is not required for PKC upregulation of hERG expression; chronic PMA treatment ( $30 \mathrm{nM}, 16$ hours) increased expression of $\Delta 2$ 354 hERG channels (Fig. 9C). Furthermore, the increased protein expression is associated with an increase in current $\left(\mathrm{I}_{\Delta 2-354 \mathrm{hERG}}\right)$ (Fig. 9D) without shifting the activation curve (Fig. 9E). The PMA-mediated increases in $\Delta 2-354 \mathrm{hERG}$ expression (Fig. 9C) and $\mathrm{I}_{\Delta 2-354 \mathrm{hERG}}$ (Fig. 9D) were prevented by the presence of BIM-1 $(10 \mu \mathrm{M})$, indicating that the effects are mediated through $\mathrm{PKC}$ activation.

Our results so far indicate that PKC-mediated $\mathrm{I}_{\mathrm{hERG}}$ inhibition involves N-terminus modification of hERG channels. This notion is in line with previous studies, which propose that hERG inhibition by PKC occurs through phosphorylation of sites, particularly $\mathrm{T} 74$, in the $\mathrm{N}$-terminal region (Thomas et al., 2003; Cockerill et al., 2007). In these previous studies using $\triangle$ PKC-hERG, a channel in which 17 of the 18 putative phosphorylation sites have been mutated to Ala, it was found that acute PKC activation still shifted the $V_{1 / 2}$ or inhibited the current of mutant channels (Thomas et al., 2003; Cockerill et al., 2007); however, mutations of T74 (i.e., T74A, T74V,
$\mathrm{T} 74 \mathrm{D}$, and $\mathrm{T} 74 \mathrm{E})$ resulted in nonfunctional channels, so the role of this phosphorylation site could not be examined (Thomas et al., 2003; Cockerill et al., 2007). We created T74C and T74I mutant hERG constructs. Unfortunately, neither the T74C nor T74I mutant produced a functional channel. Eight putative PKC phosphorylation sites (S354, S278, S250, $\mathrm{S} 179, \mathrm{~T} 174, \mathrm{~T} 162, \mathrm{~T} 74$, and S26) were removed by the $\Delta 2-354$ hERG mutant. To narrow down the site potentially responsible for PKC-mediated hERG inhibition, we created a 1-136 truncation mutant, $\Delta \mathrm{N} 136 \mathrm{hERG}$, which removed only T74 and S26 putative phosphorylation sites. The $\Delta$ N136 hERG mutant generated robust currents (Fig. 10). In contrast to the effects on WT hERG (Fig. 4A), acute PMA treatment (30 nM, 30 minutes $)$ did not decrease the $\Delta \mathrm{N} 136 \mathrm{hERG}$ current $\left(\mathrm{I}_{\Delta \mathrm{N} 136}\right.$ hERG) (Fig. 10A). On the other hand, chronic PMA treatment (16 hours, $30 \mathrm{nM}$ ) increased both $\mathrm{I}_{\Delta \mathrm{N} 136 \text { hERG }}$ (Fig. 10B) and $\Delta \mathrm{N} 136 \mathrm{hERG}$ protein expression (Fig. 10C). The increase in both $\mathrm{I}_{\Delta \mathrm{N} 136 \mathrm{hERG}}$ and $\Delta \mathrm{N} 136 \mathrm{hERG}$ protein expression upon chronic PMA treatment (16 hours, $30 \mathrm{nM}$ ) was prevented by the presence of STN (200 nM) (Fig. 10, B and C).

\section{Discussion}

The hERG channel plays a crucial role in cardiac repolarization, and a loss of its function is a major cause of LQTS, which can lead to dangerous arrhythmias and sudden death (Curran et al., 1995; Keating and Sanguinetti, 2001). It has been recognized that sympathetic activation related to physical or emotional stress can exacerbate cardiac events in patients with LQTS (Wilde et al., 1999; Schwartz et al., 2001; Winter et al., 2018). To that end, PKC is under investigation as a potential link between stress conditions and reduced hERG function; however, controversial effects of PKC on hERG function have been reported (Thomas et al., 2003; Cockerill et al., 2007; Wang et al., 2008, 2009, 2014; Chen et al., 2010; Krishnan et al., 2012; Liu et al., 2017). By investigating the effects of PKC activation on both hERG current and expression on a time scale ranging from minutes to hours, our data, for the first time, uncovered that PKC differentially regulates hERG protein expression and function; PKC activation chronically enhances channel expression (hours) through delaying channel degradation while inhibiting channel function with a faster time course (tens of minutes) through a mechanism that involves the $\mathrm{N}$ terminus of the channel.

Our results showed that $\mathrm{PKC}$ activation inhibited $\mathrm{I}_{\mathrm{hERG}}$ and positively shifted the $V_{1 / 2}$ of channel activation by approximately $10 \mathrm{mV}$ after a 30-minute PMA (30 nM) application (Fig. 4, A and B). This observation is consistent with previous literature investigating acute PKC activation (Thomas et al., 2003; Cockerill et al., 2007; Wang et al., 2008, 2009; Liu et al., 2017). Our results further demonstrated that PKC-mediated $\mathrm{I}_{\mathrm{hERG}}$ inhibition is slowly reversible. Although a 16-hour treatment with PMA (30 $\mathrm{nM}$ ) led to inhibition of $\mathrm{I}_{\mathrm{hERG}}$ and a positive shift in $V_{1 / 2}$, replacement of PMA media with fresh media resulted in a gradual increase of $\mathrm{I}_{\mathrm{hERG}}$, which became larger than $\mathrm{I}_{\mathrm{hERG}}$ of control cells after 4 hours of recovery, and $V_{1 / 2}$ of activation returned to control (Fig. 4, C and D). We propose that replacement of the media resulted in the gradual removal of a reversible modification from the channel, allowing for recovery of $I_{h E R G}$ from inhibition. The fact that $I_{h E R G}$ in PMA-treated cells after recovery is greater than that in control 
A
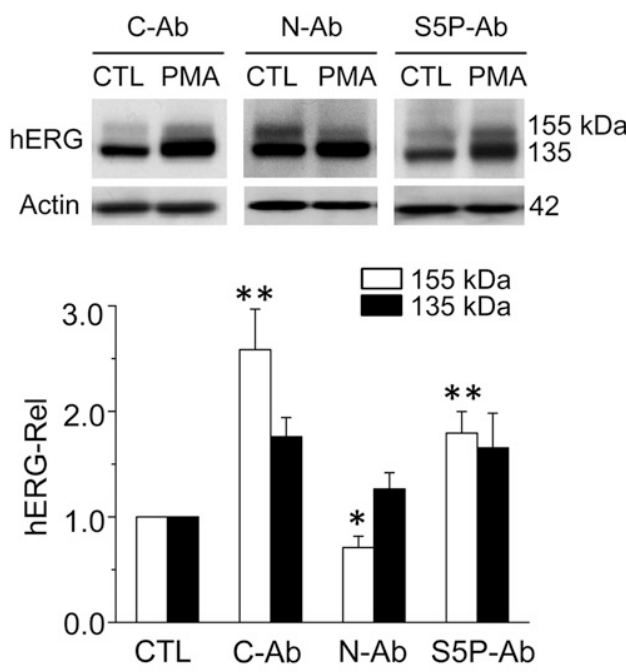

B

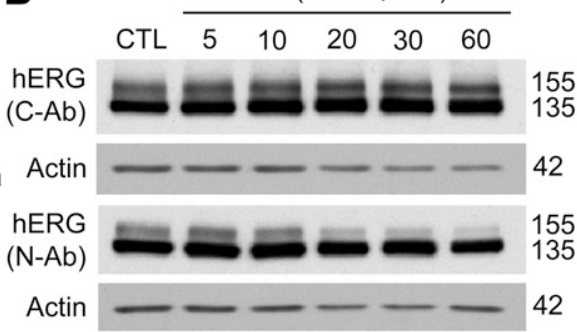

C
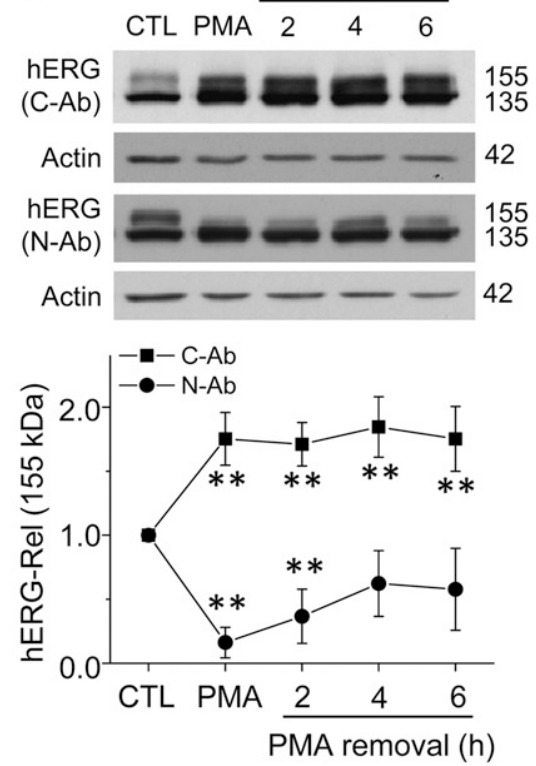

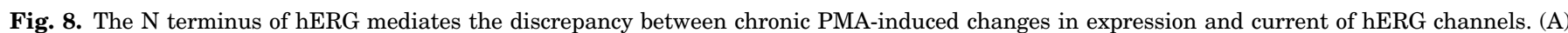

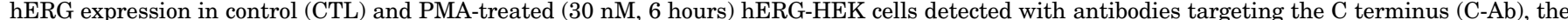

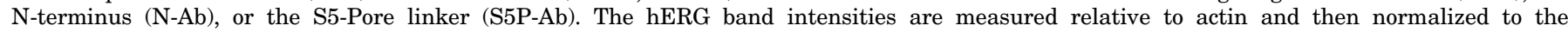

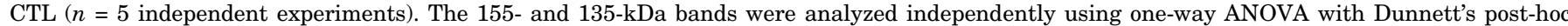

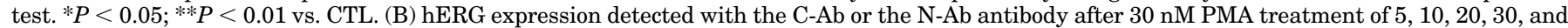

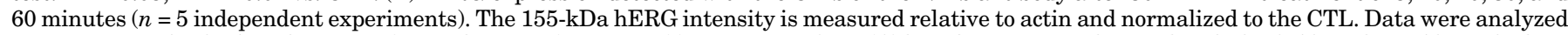

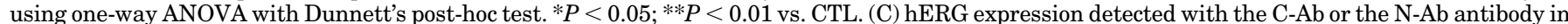

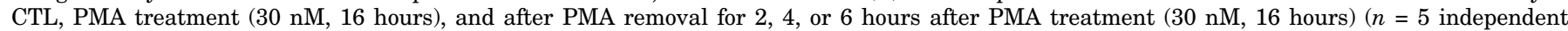

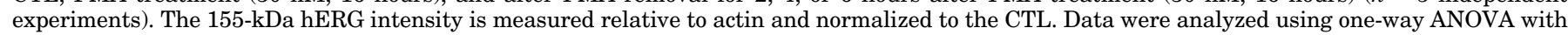
Dunnett's post-hoc test. ${ }^{* *} P<0.01$ vs. CTL.

cells demonstrates that the increased channel proteins after PKC activation are not only membrane-bound, but also functional. hERG protein turnover time is around 12 hours (Ficker et al., 2003). We demonstrated that, upon PMA removal, the recovery of inhibited channel function is faster than hERG protein turnover, resulting in greater $\mathrm{I}_{\mathrm{hERG}}$ in PMA-treated cells owing to increased hERG protein (Fig. 4C; Fig. 8C).

Our Western blot analysis revealed novel evidence of PMAmediated modification of the $\mathrm{N}$ terminus of hERG channels. After chronic PMA treatment, an increase in mature hERG expression was evident using a C-terminal antibody (Fig. 1; Fig. 2A), as well as with a S5P-binding antibody (Fig. 8A); however, detection of the same samples using an N-terminaltargeting antibody showed decreased expression of the mature hERG protein (Fig. 8A). We propose that PKC-mediated modulation of the $\mathrm{N}$-terminal region of hERG interferes with the antibody-binding epitope and is involved in the inhibition of hERG. With 5- to 60-minute treatments of hERG-HEK cells with PMA, hERG expression was not changed when detected using the C-terminal antibody. However, detection using the N-terminal antibody demonstrated a time-dependent decrease in mature hERG expression (Fig. 8B) that was associated with decreased $\mathrm{I}_{\mathrm{hERG}}$ (Fig. 4A). Furthermore, a 16-hour treatment with PMA ( $30 \mathrm{nM})$ led to both reduction in $\mathrm{I}_{\mathrm{hERG}}$ (Fig. 4C) and mature hERG detection with the anti-Nterminal antibody (Fig. 8C). Removal of PMA resulted in recovery of $\mathrm{I}_{\mathrm{hERG}}$ (Fig. $4 \mathrm{C}$ ) and recovery of mature hERG detection with the anti-N-terminal antibody (Fig. 8C). These results indicate that $\mathrm{PKC}$-mediated $\mathrm{I}_{\mathrm{hERG}}$ inhibition involves $\mathrm{N}$-terminus modification of channels. This conclusion is in line with previous studies that have proposed that hERG inhibition by PKC occurs through phosphorylation of sites, particularly T74, in the N-terminal region (Cockerill et al., 2007; Liu et al., 2017); however, mutations of T74 resulted in nonfunctional channels, so the role of T74 in PKC- mediated $\mathrm{I}_{\mathrm{hERG}}$ inhibition could not be directly examined (Thomas et al., 2003; Cockerill et al., 2007). In the present study, we demonstrated that PMA treatment of 30 minutes did not decrease the current of $\Delta 2-354$ or $\Delta$ N136 hERG mutant channels. Moreover, PMA treatment of 16 hours increased both expression and current of $\Delta 2-354$ and $\Delta$ N136 hERG mutant channels. Therefore, the $\mathrm{N}$ terminus is required for PKC-mediated inhibition of hERG channel function but not for PKC-mediated increase in expression. Consistent with previous studies (Thomas et al., 2003; Cockerill et al., 2007), our results demonstrated that disrupting the putative T74 phosphorylation site by new mutations, T74C and T74I, led to nonfunctional channels; however, our results showed that deletion of the two putative phosphorylation sites S26 and T74 (i.e., $\Delta$ N136) abolished the acute PMA treatment (30 minutes)-mediated inhibition of hERG currents (Fig. 10A). Since removal of the putative phosphorylation sites, including S26, did not affect PMA-mediated effects on hERG current (Thomas et al., 2003; Cockerill et al., 2007), these results strongly support the notion that PMA targets residue $\mathrm{T} 74$ to mediate the inhibition of $\mathrm{I}_{\mathrm{hERG}}$.

The PKC-mediated hERG increase may not be due to enhanced transcription since hERG mRNA level was not affected by 2 and 6 hours of PMA treatment (Fig. 3C). On the other hand, our results revealed that the degradation rate of mature hERG was reduced after PMA treatment. In hERG-HEK cells treated 

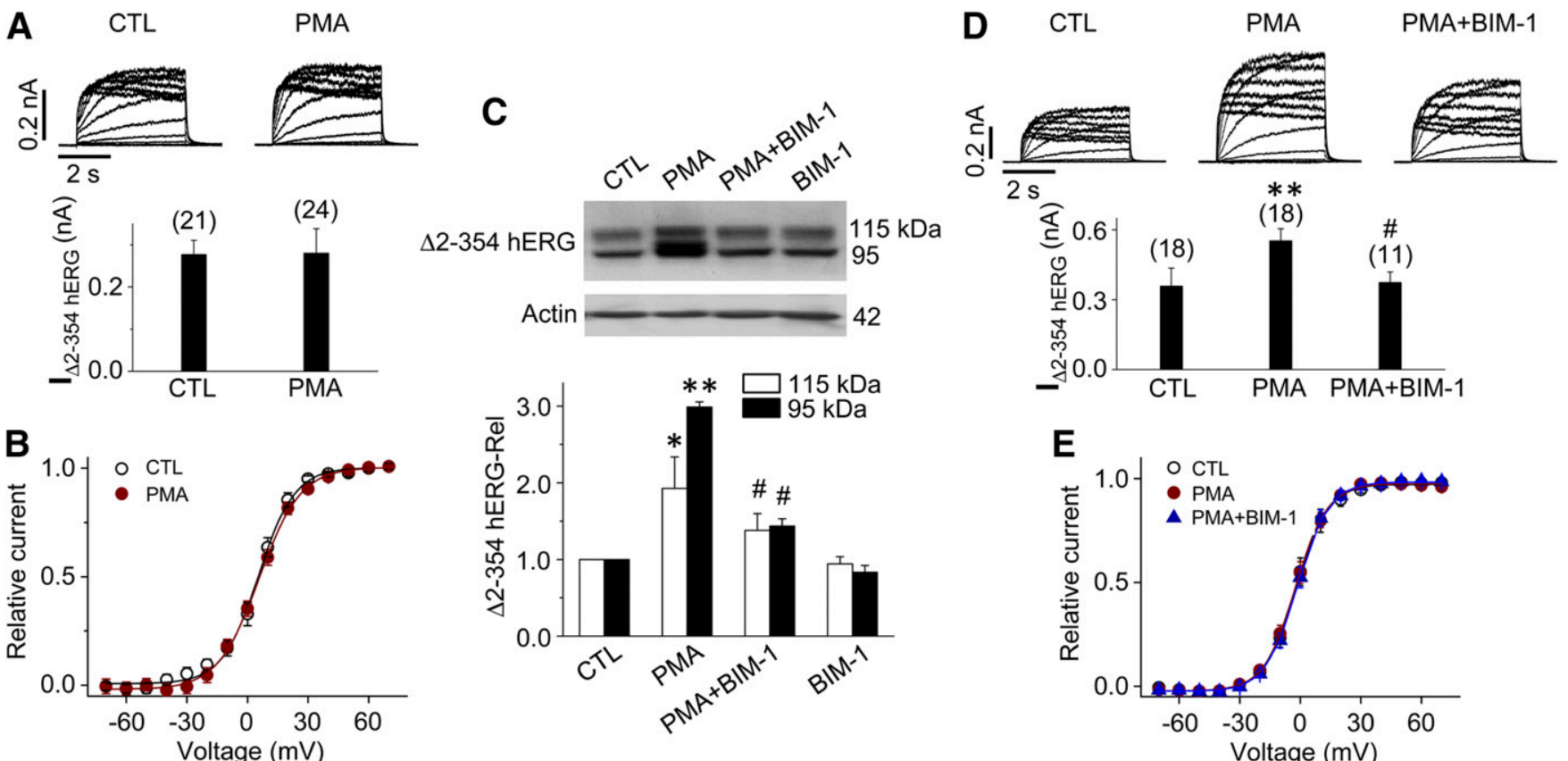

Fig. 9. PKC activation does not acutely (30 minutes) affect $\Delta 2-354$ hERG current amplitude or voltage dependence of activation, but it chronically (16 hours) increases its current amplitude and protein expression. (A) Representative currents and summarized $\mathrm{I}_{\Delta 2-354} \mathrm{hERG}$ in control (CTL) $\Delta 2-354$ hERG-HEK cells and those acutely (30 minutes) treated with PMA (30 nM). Numbers of cells recorded from four independent experiments are shown above the summarized data. There was no significant difference in $\mathrm{I}_{\Delta 2-354 \mathrm{hERG}}\left(P>0.05\right.$, unpaired $t$ test). (B) Voltage-dependence of $\mathrm{I}_{\Delta 2-354} \mathrm{hERG}$ activation in CTL $\Delta 2-354$ hERG-HEK cells and those acutely (30 minutes) treated with PMA (30 nM). $V_{1 / 2}$ and slope-factor values were determined by nonlinear regression fitting of the activation-voltage curve of $\Delta 2-354 \mathrm{hERG}$ currents from each cell to the Boltzmann function, and data from 21 to 24 cells in each group were summarized. Whereas the figure shows the fitting curve of the averaged data points, the S.E.M. values reported as follows were summarized from fitting the data from each individual cell. CTL $V_{1 / 2}: 5.4 \pm 0.6 \mathrm{mV}$; slope factor: $9.0 \pm 0.6 \mathrm{mV}$; PMA $V_{1 / 2}: 5.7 \pm 0.4 \mathrm{mV}$; slope factor: $10.3 \pm 0.4 \mathrm{mV}$. No significant differences were found in $V_{1 / 2}$ or slope factor $(P>0.05$ vs. CTL, unpaired $t$ tests). (C) Protein expression of $\Delta 2-354 \mathrm{hERG}$ in CTL $\Delta 2-354 \mathrm{hERG-}$ HEK cells and those chronically (16 hours) treated with PMA ( $30 \mathrm{nM})$, PMA ( $30 \mathrm{nM})+$ BIM-1 $(10 \mu \mathrm{M})$, or BIM-1 (10 $\mu$ M). The 115 - and 95-kDa bands were analyzed independently using one-way ANOVA with Tukey's post-hoc test. ${ }^{*} P<0.05 ; * * P<0.01$ vs. CTL; ${ }^{*} P<0.05$ vs. PMA. $n=4$ independent experiments. (D) Representative currents and summarized I ${ }_{22-354} \mathrm{hERG}$ in CTL $\Delta 2$-354 hERG-HEK cells and those chronically (16 hours) treated with PMA (30 nM) or PMA (30 nM) + BIM-1 (10 $\mu \mathrm{M})$. Numbers of cells recorded from four independent experiments are shown above the summarized data. $\mathrm{I}_{\Delta 2-354} \mathrm{hERG}$ was analyzed using data from cells with one-way ANOVA with Tukey's post-hoc test. $* * P<0.01$ vs. CTL; ${ }^{*} P<0.05$ vs. PMA. (E) Voltage dependence of $\mathrm{I}_{\Delta 2-354} \mathrm{hERG}$ activation in CTL $\Delta 2$-354 hERG-HEK cells and those chronically ( 16 hours) treated with PMA ( $\left.30 \mathrm{nM}\right)$, or PMA ( $\left.30 \mathrm{nM}\right)+\mathrm{BIM}-$ $1(10 \mu \mathrm{M}) . V_{1 / 2}$ and slope-factor values were determined by nonlinear regression fitting of the activation-voltage curve of $\Delta 2-354 \mathrm{hERG}$ currents from each cell to the Boltzmann function and data from 11 to 18 cells in each group were summarized. Whereas the figure shows the fitting curve of the averaged data points, the S.E.M. values reported as follows were summarized from fitting the data from each individual cell. CTL $V_{1 / 2}: 3.3 \pm 1.3 \mathrm{mV}$; slope factor, $8.0 \pm 0.3 \mathrm{mV}$; PMA $V_{1 / 2}: 3.7 \pm 1.2 \mathrm{mV}$; slope factor: $8.1 \pm 0.6 \mathrm{mV}$; PMA + BIM-1 $V_{1 / 2}: 3.9 \pm 1.2 \mathrm{mV}$; slope factor: $8.4 \pm 0.6 \mathrm{mV}$. No significant differences were found in $V_{1 / 2}$ or slope factor $(P>0.05$, one-way ANOVA).

with cycloheximide (a protein synthesis inhibitor) and brefeldin A (an ER to Golgi transit inhibitor), PMA treatment slowed the degradation of $155-\mathrm{kDa}$ hERG proteins (Fig. 3D). PMA treatment also led to an increase in phosphorylated Nedd4-2 without affecting total Nedd4-2 level (Fig. 3E), indicating that PMA treatment inhibits Nedd4-2 activity. Since Nedd4-2 mediates hERG degradation (Guo et al., 2012), its inhibition by PMA treatment would result in reduced ubiquitination and degradation of hERG, leading to accumulation of mature channels in the plasma membrane. Previous studies demonstrated that PKC mediated inhibition of Nedd4-2 through the serum- and glucocorticoid-inducible kinase, as well as muscarinic acetylcholine M3 receptor delays hERG degradation, leading to increased hERG expression (Lamothe and Zhang, 2013; Wang et al., 2014). Nonetheless, other mechanisms should also be considered. For example, previous studies have proposed that chronic PKC activation enhances hERG expression through accelerated post-transcriptional channel synthesis (Chen et al., 2010; Krishnan et al., 2012).

It is important to note that the regulation of hERG by PKC may be shaped by the unique profile of PKC isoenzymes activated by specific signaling pathways. Our data showed that treatment of hERG-HEK cells with $30 \mathrm{nM}$ PMA caused a time-dependent depletion of the expression level of PKC $\alpha$ and $\operatorname{PKC} \theta$, but it did not affect the expression of $\mathrm{PKC} \beta, \operatorname{PKC} \varepsilon$, $\mathrm{PKC} \sigma, \mathrm{PKC} \iota$, and $\mathrm{PKC} \lambda$ up to 18 hours (Fig. 7). Moreover, the depletion became obvious only after 6-hour treatment (Fig. 7). PMA-induced $\mathrm{I}_{\mathrm{hERG}}$ inhibition occurred at 30 minutes (Fig. 4A), and PMA-induced increase in hERG expression occurred at 4 hours (Fig. 1A). Thus, PKC depletion may not play an essential role in PMA-mediated effects on hERG channels in hERG-HEK cells. PMA activates various PKC isozymes (McFerran et al., 1995), whereas specific PKC isoform signaling can be achieved by the activation of distinct $\mathrm{G}$ proteincoupled receptor pathways (Liu et al., 2017). Nonetheless, there are some similarities in $\mathrm{hERG} / \mathrm{I}_{\mathrm{Kr}}$ responses to $\mathrm{PKC}$ activation induced by PMA and $\alpha 1-\mathrm{AR}$ or $\mathrm{M} 3$ receptor stimulation. For example, acute agonism of $\alpha 1$-AR or M3 receptors inhibits hERG current and positively shifts $V_{1 / 2}$ in a manner that involves the $\mathrm{N}$ terminus of hERG (Thomas et al., 2004b; Cockerill et al., 2007; Liu et al., 2017), whereas chronic activation of $\alpha 1$-AR or M3 receptors increases hERG expression and current (Chen et al., 2010; Wang et al., 2014; Mahati et al., 2016). On the other hand, angiotensin II-mediated PKC 
A

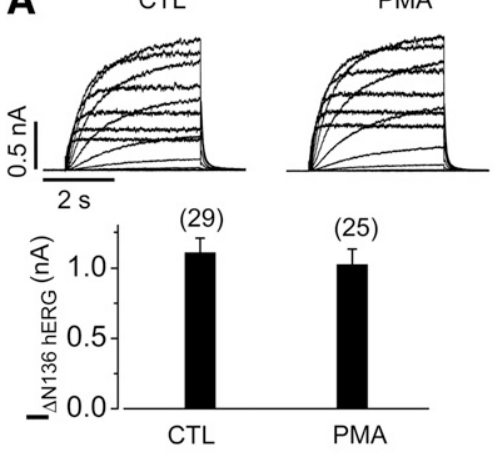

B
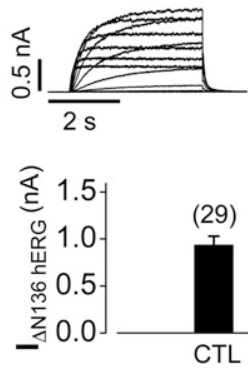

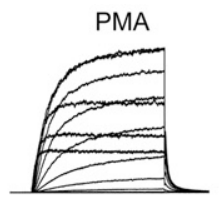

**

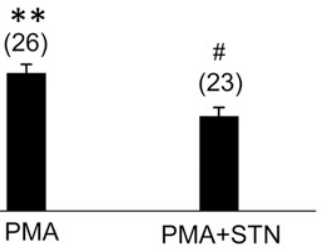

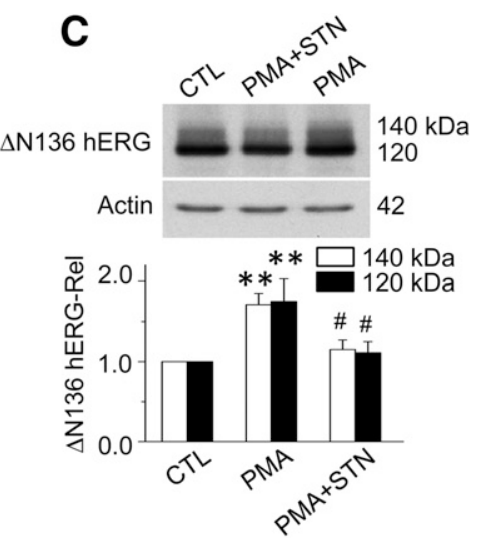

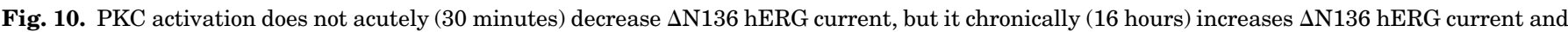

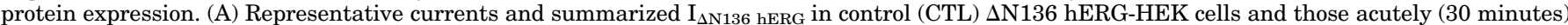

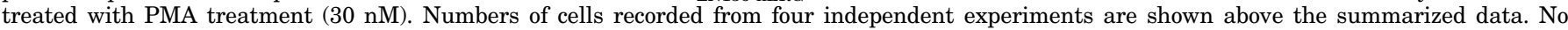

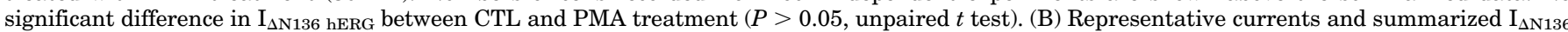

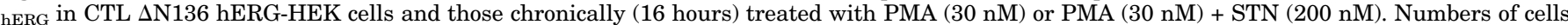

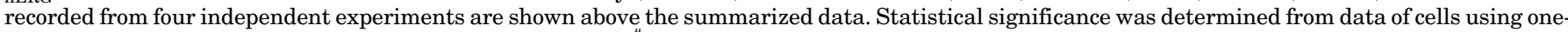

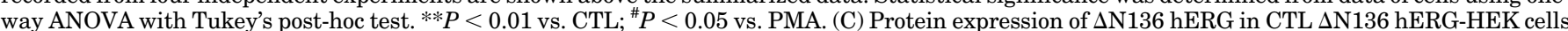

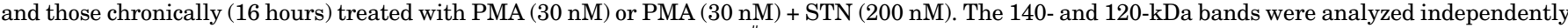
using one-way ANOVA with Tukey's post-hoc test. ${ }^{*} P P<0.01$ vs. CTL; ${ }^{\#} P<0.05$ vs. PMA. $n=4$ independent experiments.

activation inhibits $\mathrm{I}_{\mathrm{hERG}}$ but does not shift $V_{1 / 2}$, and the $\mathrm{N}$ terminus of hERG is not involved in the inhibition (Liu et al., 2017). It was proposed that PKC $\alpha$ mediates $\mathrm{I}_{\mathrm{hERG}}$ inhibition after $\alpha 1$-AR activation, whereas $\mathrm{PKC} \varepsilon$ mediates inhibition after $\mathrm{AT}_{1}$ receptor activation (Liu et al., 2017). Future investigations are required to uncover specific isoenzymes and downstream pathways involved in hERG regulation with aspects of functional regulation versus channel expression. In addition, although the effects of both acute (30 minutes) and chronic (16 hours) PMA treatment were similar for $\mathrm{I}_{\mathrm{hERG}}$ in $\mathrm{HEK}$ cells and $\mathrm{I}_{\mathrm{Kr}}$ in cardiomyocytes, chronic PMA-induced increase in $\mathrm{I}_{\mathrm{hERG}}$ recorded from HEK cells was seen only after 4 hours of PMA removal (Fig. 4C), but chronic PMA-induced increase in $\mathrm{I}_{\mathrm{Kr}}$ recorded from ventricular myocytes was observed immediately after treatment (Fig. 5B). The molecular mechanisms for such a difference are complex and warrant future investigation. Differences in endogenous PKC isoenzymes and phosphatases, as well as their responses to prolonged PMA treatment could be responsible. Moreover, there is a possibility that PKC activation results in the activation of another kinase that then phosphorylates the hERG channel. Future studies in a more purified system with a purified kinase will be required to demonstrate a direct phosphorylation by specific enzymes/kinases.

In summary, we have demonstrated that PMA-mediated PKC activation regulates hERG channels through two opposing mechanisms: increasing hERG expression and decreasing hERG current. Whereas PMA-mediated PKC activation is not physiologic, our data nonetheless raise the possibility that a buffer system may exist regarding PKC-mediated hERG regulation whereby $\mathrm{PKC}$-mediated hERG current inhibition is countered by an increase in hERG channel abundance.

\section{Authorship Contributions}

Participated in research design: Sutherland-Deveen, Wang, Lamothe, Zhang.

Conducted experiments: Sutherland-Deveen, Wang, Lamothe, Guo, Li, Yang, Du.
Performed data analysis: Sutherland-Deveen, Wang, Tschirhart, Guo, Li, Yang.

Wrote or contributed to the writing of the manuscript: SutherlandDeveen, Wang, Zhang.

\section{References}

Alessi DR (1997) The protein kinase C inhibitors Ro 318220 and GF 109203X are equally potent inhibitors of MAPKAP kinase-1beta (Rsk-2) and p70 S6 kinase. FEBS Lett 402:121-123.

Chen J, Chen K, Sroubek J, Wu ZY, Thomas D, Bian JS, and McDonald TV (2010) Post-transcriptional control of human ether-a-go-go-related gene potassium channel protein by alpha-adrenergic receptor stimulation. Mol Pharmacol 78:186-197.

Cockerill SL, Tobin AB, Torrecilla I, Willars GB, Standen NB, and Mitcheson JS (2007) Modulation of hERG potassium currents in HEK-293 cells by protein kinase C. Evidence for direct phosphorylation of pore forming subunits. J Physiol 581: 479-493.

Curran ME, Splawski I, Timothy KW, Vincent GM, Green ED, and Keating MT (1995) A molecular basis for cardiac arrhythmia: HERG mutations cause long QT syndrome. Cell 80:795-803.

Debonneville C, Flores SY, Kamynina E, Plant PJ, Tauxe C, Thomas MA, Münster C, Chraïbi A, Pratt JH, Horisberger JD, et al. (2001) Phosphorylation of Nedd4-2 by Sgk1 regulates epithelial $\mathrm{Na}(+)$ channel cell surface expression. EMBO J 20: $7052-7059$

Ebinu JO, Stang SL, Teixeira C, Bottorff DA, Hooton J, Blumberg PM, Barry M, Bleakley RC, Ostergaard HL, and Stone JC (2000) RasGRP links T-cell receptor signaling to Ras. Blood 95:3199-3203.

Ficker E, Dennis AT, Wang L, and Brown AM (2003) Role of the cytosolic chaperones Hsp70 and Hsp90 in maturation of the cardiac potassium channel HERG. Circ Res 92:e87-e100.

Gang $\mathrm{H}$ and Zhang $\mathrm{S}(2006) \mathrm{Na}^{+}$permeation and block of hERG potassium channels. $J$ Gen Physiol 128:55-71.

Guo J, Massaeli H, Li W, Xu J, Luo T, Shaw J, Kirshenbaum LA, and Zhang S (2007) Identification of $\mathrm{I}_{\mathrm{Kr}}$ and its trafficking disruption induced by probucol in cultured neonatal rat cardiomyocytes. J Pharmacol Exp Ther 321:911-920.

Guo J, Wang T, Li X, Shallow H, Yang T, Li W, Xu J, Fridman MD, Yang X, and Zhang S (2012) Cell surface expression of human ether-a-go-go-related gene (hERG) channels is regulated by caveolin-3 protein via the ubiquitin ligase Nedd42. J Biol Chem 287:33132-33141.

Heath BM and Terrar DA (2000) Protein kinase C enhances the rapidly activating delayed rectifier potassium current, $\mathrm{I}_{\mathrm{Kr}}$, through a reduction in C-type inactivation in Guinea-pig ventricular myocytes. J Physiol 522:391-402.

Keating MT and Sanguinetti MC (2001) Molecular and cellular mechanisms of cardiac arrhythmias. Cell 104:569-580.

Krishnan Y, Li Y, Zheng R, Kanda V, and McDonald TV (2012) Mechanisms underlying the protein-kinase mediated regulation of the HERG potassium channel synthesis. Biochim Biophys Acta 1823:1273-1284

Lamothe SM, Guo J, Li W, Yang T, and Zhang S (2016) The human ether-a-go-gorelated gene (hERG) potassium channel represents an unusual target for proteasemediated damage. J Biol Chem 291:20387-20401.

Lamothe SM and Zhang S (2013) The serum- and glucocorticoid-inducible kinases SGK1 and SGK3 regulate hERG channel expression via ubiquitin ligase Nedd4-2 and GTPase Rab11. J Biol Chem 288:15075-15084.

Liu X, Wang Y, Zhang H, Shen L, and Xu Y (2017) Different protein kinase C isoenzymes mediate inhibition of cardiac rapidly activating delayed rectifier $\mathrm{K}^{+}$ current by different G-protein coupled receptors. Br J Pharmacol 174:4464-4477. 
Livak KJ and Schmittgen TD (2001) Analysis of relative gene expression data using real-time quantitative PCR and the 2(-delta delta C(T)) method. Methods 25: 402-408.

Mahati E, Li P, Kurata Y, Maharani N, Ikeda N, Sakata S, Ogura K, Miake J, Aiba T, Shimizu W, et al. (2016) M3 muscarinic receptor signaling stabilizes a novel mutant human ether-a-go-go-related gene channel protein via phosphorylation of heat shock factor 1 in transfected cells. Circ $J \mathbf{8 0}$ 2443-2452.

McFerran BW, MacEwan DJ, and Guild SB (1995) Involvement of multiple protein kinase $\mathrm{C}$ isozymes in the ACTH secretory pathway of AtT-20 cells. Br J Pharmacol 115:307-315.

Roberts NA, Haworth RS, and Avkiran M (2005) Effects of bisindolylmaleimide PKC inhibitors on p90RSK activity in vitro and in adult ventricular myocytes. $\mathrm{Br} J$ Pharmacol 145:477-489.

Sanguinetti MC, Jiang C, Curran ME, and Keating MT (1995) A mechanistic link between an inherited and an acquired cardiac arrhythmia: $H E R G$ encodes the $\mathrm{I}_{\mathrm{Kr}}$ potassium channel. Cell 81:299-307.

Schwartz PJ, Priori SG, Spazzolini C, Moss AJ, Vincent GM, Napolitano C, Denjoy I, Guicheney P, Breithardt G, Keating MT, et al. (2001) Genotype-phenotype correlation in the long-QT syndrome: gene-specific triggers for life-threatening arrhythmias. Circulation 103:89-95.

Thomas D, Hammerling BC, Wimmer AB, Wu K, Ficker E, Kuryshev YA, Scherer D, Kiehn J, Katus HA, Schoels W, et al. (2004a) Direct block of hERG potassium channels by the protein kinase C inhibitor bisindolylmaleimide I (GF109203X). Cardiovasc Res 64:467-476.

Thomas D, Wu K, Wimmer AB, Zitron E, Hammerling BC, Kathöfer S, Lueck S, Bloehs R, Kreye VA, Kiehn J, et al. (2004b) Activation of cardiac human ether-ago-go related gene potassium currents is regulated by alpha(1A)-adrenoceptors. $J$ Mol Med (Berl) 82:826-837.

Thomas D, Zhang W, Wu K, Wimmer AB, Gut B, Wendt-Nordahl G, Kathöfer S, Kreye VA, Katus HA, Schoels W, et al. (2003) Regulation of HERG potassium channel activation by protein kinase $\mathrm{C}$ independent of direct phosphorylation of the channel protein. Cardiovasc Res 59:14-26.

Triposkiadis F, Karayannis G, Giamouzis G, Skoularigis J, Louridas G, and Butler J (2009) The sympathetic nervous system in heart failure physiology, pathophysiology, and clinical implications. J Am Coll Cardiol 54:1747-1762.
Trudeau MC, Warmke JW, Ganetzky B, and Robertson GA (1995) HERG, a human inward rectifier in the voltage-gated potassium channel family. Science 269:92-95.

Tschirhart JN, Li W, Guo J, and Zhang S (2019) Blockade of the human ether a-go-gorelated gene (hERG) potassium channel by fentanyl. Mol Pharmacol 95:386-397.

Wang J, Trudeau MC, Zappia AM, and Robertson GA (1998) Regulation of deactivation by an amino terminal domain in human ether-à-go-go-related gene potassium channels. J Gen Physiol 112:637-647.

Wang S, Xu DJ, Cai JB, Huang YZ, Zou JG, and Cao KJ (2009) Rapid component I( $\mathrm{Kr}$ ) of cardiac delayed rectifier potassium currents in Guinea-pig is inhibited by alpha(1)-adrenoreceptor activation via protein kinase $\mathrm{A}$ and protein kinase C-dependent pathways. Eur J Pharmacol 608:1-6.

Wang T, Hogan-Cann A, Kang Y, Cui Z, Guo J, Yang T, Lamothe SM, Li W, Ma A, Fisher JT, et al. (2014) Muscarinic receptor activation increases hERG channel expression through phosphorylation of ubiquitin ligase Nedd4-2. Mol Pharmacol 85:877-886.

Wang YH, Shi CX, Dong F, Sheng JW, and Xu YF (2008) Inhibition of the rapid component of the delayed rectifier potassium current in ventricular myocytes by angiotensin II via the AT1 receptor. Br J Pharmacol 154:429-439.

Wilde AA, Jongbloed RJ, Doevendans PA, Düren DR, Hauer RN, van Langen IM, van Tintelen JP, Smeets HJ, Meyer H, and Geelen JL (1999) Auditory stimuli as a trigger for arrhythmic events differentiate HERG-related (LQTS2) patients from KVLQT1-related patients (LQTS1). J Am Coll Cardiol 33:327-332.

Winter J, Tipton MJ, and Shattock MJ (2018) Autonomic conflict exacerbates long QT associated ventricular arrhythmias. $J$ Mol Cell Cardiol 116:145-154.

Zhang S (2006) Isolation and characterization of $\mathrm{I}(\mathrm{Kr})$ in cardiac myocytes by $\mathrm{Cs}^{+}$ permeation. Am J Physiol Heart Circ Physiol 290:H1038-H1049.

Zhou Z, Gong Q, Ye B, Fan Z, Makielski JC, Robertson GA, and January CT (1998) Properties of HERG channels stably expressed in HEK 293 cells studied at physiological temperature. Biophys J 74:230-241.

Address correspondence to: Dr. Shetuan Zhang, Department of Biomedical and Molecular Sciences, Queen's University, 18 Stuart Street, Botterell Hall, Room 439, Kingston, ON K7L 3N6, Canada. E-mail: shetuan.zhang@ queensu.ca 